\title{
THE SIGNIFICANCE OF SUFFERING IN ORGANIZATIONS: UNDERSTANDING VARIATION IN WORKERS' RESPONSES TO MULTIPLE MODES OF CONTROL
}

\author{
MICHAEL J. GILL \\ University of Oxford
}

\begin{abstract}
I develop a framework to explain workers' diverse responses to similar combinations of control modes across organizations. The framework highlights the importance of two conceptual dimensions that draw together insights from studies of control and resistance in the workplace. The dimension of compatibility considers workers' subjective experiences of the fit between their personhood and modes of control, where alignment can inspire fulfillment and misalignment can prompt suffering. The dimension of coherence considers workers' perception of the consistency between modes, which can be fragmented or unified to reinforce organizationally prescribed goals and processes. The framework yields four ideal types of interaction between modes of control: complementing, coexisting, competing, and clashing. I illustrate how workers experience each ideal type through empirical examples and, in doing so, identify how workers' experiences can trigger processes that generate different intensities of compliance and resistance to control.
\end{abstract}

Managerial and organizational research has typically emphasized how the control of workers is necessary to ensure the success and survival of organizations. As Barker pointed out, for any organization to move toward its goals and purposes, "Its members must interactively negotiate and implement some type of strategy that effectively controls members' activities in a manner functional for the organization" (1993: 409).

In exploring the effectiveness of particular strategies or modes of control, the corpus of critical management studies has revealed considerable variation. Organizations' deployment of similar modes of control often appears to yield contradictory outcomes in different settings. For instance, the combination of bureaucratic and normative modes of control to encourage workers' autonomy and empowerment in the workplace can prompt the responses of intense commitment (Barker, 1999), a mix of ambivalence and enhanced commitment (McLoughlin, Badham, \& Palmer, 2005), superficial compliance (Bolton, 2004), or rejection (Ezzamel \& Willmott, 1998). The extant critical literature offers little theory about

This article would not have been possible without the help of David Gill. I would like to thank Hugh Willmott for his guidance throughout the evolution of the manuscript. I am grateful to the three anonymous reviewers for their thoughtful comments. Thank you also to those who commented on earlier drafts, including Martin Parker, Yiannis Gabriel, Tom Lawrence, Tim Morris, Andrew Sturdy, and Sally Maitlis. the reasons for this variance across organizations. Yet understanding workers' varying responses is important because it informs our understanding of how and why control is accepted or resisted at different times in contemporary organizations.

Critical scholarship does, however, point to two important considerations in understanding workers' diverse responses. The first is workers' subjective experiences of organizational control, which are mediated by their unique economic, historical, and social context (Knights \& Willmott, 1989). For instance, workers may willingly reproduce modes of control that they interpret as compatible with their self-identity (Willmott, 1993) and as important in sustaining their autonomous sense of self (Ashforth \& Humphrey, 1993). The second consideration is the potential for workers to experience multiple modes of control operating within organizations as coherent so that they reinforce one another (Storey, 1985). Different degrees of coherence can prompt different interactions between modes of control (Alvesson \& Körreman, 2004; Callaghan \& Thompson, 2001; Ferner, 2000). Varying degrees of coherence in combinations of control can thus give rise to subtly distinct interactive effects that affect workers in different ways.

These considerations inform my development of two conceptual dimensions, which underpin a framework that helps to explain workers' diverse 
responses to multiple modes of organizational control. The dimension of compatibility describes the degree of alignment between a worker's personhood-their physical, psychological, and social qualities - and their subjective experience of organizational control. I demonstrate how alignment can be a source of fulfillment, whereas misalignment can generate suffering. The dimension of coherence describes the degree to which workers perceive two or more modes of control as logical and consistent, from fragmented to forming a unified whole. The framework yields four ideal types of interaction between modes of control that workers can experience: complementing, coexisting, competing, and clashing. These ideal types serve as analytical constructs that provide a lens through which to consider workers' reactions to control. I explore each ideal type through an empirical example, examining combinations of bureaucratic and normative modes to focus my analysis and delve into the dynamics of their interaction.

The theoretical framework makes three contributions to the extant critical research on organizations. First, I illustrate how workers experience and produce each ideal type in specific circumstances. I explicate how these experiences can trigger specific processes-blending, bridging, distancing, and separating - that generate distinctive intensities of compliance and resistance to seemingly similar arrangements of control. In doing so I reveal why workers' sense of dignity or personal loss stemming from organizational control can profoundly shape their commitment or resistance, which can be magnified when modes of control are highly coherent. These insights help to reconcile several divergent findings across different streams of critical research and help to build on scholarship that reveals the ways control unfolds in organizations (Alvesson \& Willmott, 2002; Delbridge \& Ezzomel, 2005).

Second, the ideal types help to reframe ongoing deliberations concerning the nature of resistance. I argue that each ideal type of interaction is associated with a process that prompts a different intensity of resistance, rather than a particular strategy or form (Ackroyd \& Thompson, 1999). Extending scholarship stressing that workers' experiences of and reactions to control are socially situated practices (Mumby, 2005; Mumby, Thomas, Martí, \& Seidl, 2017), my framework identifies processes that explain why different intensities of resistance may emerge, while respecting that the manifestations of such resistance are contextually constrained (Collinson, 1994; Kondo, 2009; Thomas \& Davies, 2005).

Third, a key implication of the framework is that one way workers experience suffering in organizations is when modes of control damage aspects of their personhood. While there remains a need to identify and perceive unnecessary suffering (Adler, Forbes, \& Willmott, 2007), my framework highlights that suffering is more than just an outcome of control. With reference to empirical studies, I demonstrate how suffering is also a vital explanatory concept in understanding how processes of control and resistance unfold.

Five sections structure this article. First, I elaborate on the dimension of compatibility, theorizing about the relationship among control, fulfillment, and suffering. Second, I explicate the dimension of coherence. Third, I use these two dimensions to construct a framework of four ideal types of interaction and explore each through an empirical illustration. Fourth, I discuss the boundary conditions, strengths, and limitations of this fromework. Fifth, I discuss the contributions of the framework to the critical literature and outline an associated agenda for future research.

\section{(IN)COMPATIBLE MODES OF CONTROL: CONTROL AS A SOURCE OF FULFILLMENT OR SUFFERING}

Control involves "processes of negotiation in which various strategies are developed, by workers as well as managers, to produce particular outcomes" (Coombs, Knights, \& Willmott, 1992: 58). Control is therefore a dynamic process (Child, 1984; Maguire, Phillips, \& Hordy, 2001; Marshall, 1998) that regulates behavior through an explicit or implicit set of modes, rules, or strategies (Clegg, 1981). For clarity, throughout the rest of this article I use the term worker to refer to anyone who works in an organization. Managers also participate in a relationship of subordination to an employer they depend on for their income (Watson, 1997; Willmott, 2005), and they are subjected to the same forms of redundancy and work intensification as other workers (Fournier \& Grey, 2000; Hyman, 1987; Willmott, 1997). Nonetheless, given the unequal distribution of material and symbolic resources within organizations, some individuals possess greater opportunities to define and employ strategies of organizational control than others. 
There is a wide range of literature exploring the multifaceted concept of control. Scholars have developed a variety of categorizations to delineate different modes or types of control (e.g., Blau \& Schoenherr, 1971; Child, 1972; Czarniawska-Joerges, 1988; Edwards, 1981; Etzioni, 1975; Friedman, 1977a; Mintzberg, 1993; Ouchi, 1979; Sturdy, Fleming, \& Delbridge, 2010). This scholarship has identified differing modes or targets of control. Structural or bureaucratic control regulates through rules and procedures (Blau \& Schoenherr, 1971; Blau \& Scott, 1962). Market control regulates through pricing mechanisms (Ouchi, 1979). Input control regulates behavior through the acquisition of resources, including workers (Mintzberg, 1989). Output control regulates outcomes and results, as opposed to the means by which outcomes are achieved (Ezzamel, Willmott, \& Worthington, 2001; Snell, 1992). Critical studies of the workplace have revealed that control is not limited to the regulation of individuals' observable actions or their behaviors (cf. Flamholtz, 1983; Otley \& Berry, 1980). Normative or socioideological modes of control regulate workers' emotions and thoughts, managing the "insides"-the inner hopes, fears, and aspirations-of workers, rather than their behaviors directly (Borley \& Kunda, 1992; Deetz, 1995; Fineman \& Sturdy, 1999; Tompkins \& Cheney, 1985).

A key assumption of my analysis is that workers can subjectively experience any mode of organizational control as a source of personal fulfillment or suffering. These subjective experiences offer one (partial) explanation for why workers can respond with such variety to seemingly similar combinations of control. I incorporate this assumption into the framework through the first of two conceptual dimensions, which I label "compatibility." Compatibility describes the degree of accordance between a worker's personhood and the modes of control they experience, which may target and affect multiple aspects of their personhood. Compatibility reflects the idea that organizational control can affect workers' physical and emotional well-being (Ouchi \& Johnson, 1978). I contend that when there is a good fit between the personal qualities of a worker and the affordances or requirements of organizational control, such as when organizational control maintains or promotes a sense of dignity or other positive psychological rewards, there will be a sense of fulfillment and a high degree of compatibility. When there is a poor fit, a worker will perceive aspects of their personhood as threatened, equating to a sense of suffering and a low degree of compatibility. Compatibility is a phenomenological experience that arises when individuals perceive a harmony between aspects of their personhood that they deem important and modes of control that are involved in their work activities.

In the following subsections I examine critical studies of bureaucratic and normative modes of control to clarify how workers can experience particular modes of control as compatible or incompatible with their personhood and, thus, as sources of fulfillment or suffering. This focus reflects the prominent role that both modes of control play in contemporary workplaces (Alvesson \& Thompson, 2006; Du Gay, 2000; Ezzy, 2001; Fuller \& Smith, 1991; Thompson, 2003). They are also often empirically intertwined (Ouchi, 1979; Willmott, 2011), albeit to varying degrees, which is useful given my desire to explore the interactions between modes of control. By restricting the focus to bureaucratic and normative modes, I can also more accurately discern the relationship among control, fulfillment, and suffering. In doing so I elaborate the key conceptual dimension of compatibility that will underpin a framework to explain the variation in workers' responses to multiple modes of control.

\section{Modes of Control As Compatible with the Worker: A Source of Fulfillment}

Personal fulfillment is the "degree to which organizational members accrue positive psychological rewards while working in an organizational system" (Nemiroff \& Ford, 1976: 70). Fulfillment means fostering a sense that on individual is a worthy person or raising the individual's self-worth and dignity to achieve their potential (Giddens, 1991). Work can be a source of meaning that is essential to workers' self-fulfillment (for examples see Du Gay, 1996, and Rose, 1990), and managers frequently aim to provide fulfilling work (Bartlett \& Ghoshal, 1994; Fleming, 2005). A worker's fulfillment from work can be conceived of in terms of pleasant sensations or prestige and payment (Baumeister, 1987). Critical scholars, such as Marx in his early work, argued instead that fulfillment lies in our ability to create our lives for ourselves through "free, conscious activity" (Marx \& Engels, 2009: 76). Recent studies similarly suggest that 
fulfillment often relates to the extent to which individuals are able to behave consistently with their values, maintaining or strengthening their autonomous sense of self in the process (Ryan \& Deci, 2001). As a result, workers will differ in their beliefs about what constitutes fulfillment (Wartenberg, 1982) since they possess their own values to fulfill.

To support my claim that modes of control can prompt fulfillment, I consider the example of bureaucratic control. Max Weber (1978) outlined an ideal type of bureaucratic organization as having a fixed division of labor, a hierarchy of positions and authority, an administration based on written documents, and an adherence to general rules, among other features (Walton, 2005; Weber, 1946). These characteristics stress formalization and impersonal rules as the basis for control (Edwards, 1979) to maximize efficiency in administration (Blau, 1956). The benefits of such rationality underpinning organizations have been widely discussed and help to explain the continued popularity of bureaucracy (see Du Gay, 2000, 2011). For instance, bureaucracies are not necessarily always the moral vacuums that critics claim but often rest on an ethical basis of neutrality and responsibility (Willmott, 2011). Bureaucracies thus offer a variety of benefits for workers, including constraints on management behavior, the formalization of equity, and procedural fairness of treatment to support meritocracy (Rosenthal, 2004) that can enable creative, cooperative, and fulfilling work (Adler \& Borys, 1996; Adler \& Chen, 2011).

Other modes of control, such as normative control, may also be sources of fulfillment. Most control modes, including bureaucracies, have normative dimensions since their operation and effects will often implicitly engage with hearts and minds (Ouchi, 1979). Thus, I follow Thompson and van den Broek's (2010) more restricted conception of normative control, defined as managerial controls directed toward engagement with and intended transformation of employees' emotions, identities, or values (Alvesson \& Willmott, 2002). Such control presents organizations as collectives that represent a locus of shared values and moral involvement (Barley \& Kunda, 1992). When normative control is accomplished to some degree, workers' identities or values can be bound up with dedication to the organization or work teams, leading employees to commit themselves to their work or colleagues (Barker, 1993; Casey, 1995; Körreman \& Alvesson, 2004). There are benefits for workers, too, who can experience "emotional satisfaction and social solidarity obtained from participation in the pseudo family of the work team" (Ezzy, 2001: 635). Workers' commitment to an organization can be a source of selfesteem (Abrams \& Hogg, 1988), fostering a desired identity (Anteby, 2008a) and thus facilitating a sense of fulfillment.

\section{Modes of Control As Incompatible with the Worker: A Source of Suffering}

Suffering describes the distress a person experiences when they perceive a threat to any aspect of their continued existence, whether physical, psychological, or social (Cassell, 1982, 1991a,b). Suffering can occur in relation to any feature of the person's valued characteristics, all of which are susceptible to damage and loss. Other researchers have noted that suffering results from an inability to control actions that usually define one's view of one's self and that the characteristics of suffering include the loss of autonomy (Drew, 1986) or the loss of valued relationships or sense of self (Zaza, Charles, \& Muszynski, 1998). Suffering is therefore determined not by the threat itself but, rather, by its meaning to the individual and the threat to their personhood. It is important to clarify that feelings accompany experiences of suffering. Injuries to the existence of the person may be expressed by a range of emotions or mental states (e.g., anxiety, burnout, depression, loneliness). This is, however, the outward expression of the injury and not the injury itself (Cassell, 199la).

Turning again to the example of bureaucratic control, there is a long-established body of literature examining the costs to workers of bureaucracy, in its various forms (Adler, 2011; Arendt, 1970; Braverman, 1974; Gouldner, 1954; Martin, Knopoff, \& Beckman, 1998). As Ritzer (2008: 26) explained, "Despite the advantages it offers ... a bureaucracy can be a dehumanizing place in which to work" by treating people as automatons. Through observing, evaluating, and rewarding workers in ways that "individualize" them (McCabe, 2015), this mode of control risks dehumanizing relationships (Hummel, 2007). Numerous organizational scholars have pointed to the presence of dehumanization in bureaucratic organizations (Alvesson \& Thompson, 2006; Cunliffe \& Jun, 2005; Victor \& Stephens, 1994), even in modern professional service settings (Hirst \& 
Humphreys, 2015; McCabe, 2015). Indeed, Bauman (1989) argued that dehumanization is an inescapable function of bureaucracies that can threaten workers' sense of self and valued relationships with others, thereby generating suffering.

Normative control, with its promotion of shared identities and values within an organization, can also be a source of suffering. It can encourage some degree of worker deindividuation or the deemphasizing of individual differences so that workers' individual preferences are replaced by common goals (Kanter, 1972; Rafaeli \& Pratt, 1993). Critical research examining the prescription of appropriate shared identities or values has highlighted the loss of authentic selves, as organizations partially eliminate the conditions for facilitating self-determination (Casey, 1995; Dahler-Larsen, 1994) and penetrate the private realm (Delbridge, 1998). Kunda explained that "members report feeling intense pressure, an invasion of their private life by corporate requirements, and, in many cases, considerable personal suffering, manifested in burnout and associated forms of despair" (1992: 223).

\section{(IN)COHERENT MODES OF CONTROL: MULTIPLE MODES AS FRAGMENTED OR UNIFIED}

Contemporary organizations frequently employ multiple modes of control simultaneously (Gabriel, 1999; Lukes, 1974). This is distinct from the idea that modes of control replace one another (Edwards, 1979) or alternate (Friedman, 1977a). As Clegg pointed out, such views lack "an adequate theorization of the organization as a complex unity of distinct types of control" (1981: 551). Multiple modes of control within organizations have been examined and described variously as clusters (Storey, 1985), combinations (Bolton, 2004; Edwards, 1979; Ferner, 2000), constellations (Zanoni \& Janssens, 2007), hybrids (Clegg, Courpasson, \& Phillips, 2006; Reed, 2010; Thompson \& McHugh, 1995), a mix (Jermier, 1998), and regimes (Delbridge, Turnbull, \& Wilkinson, 1992; Thompson \& van den Broek, 2010). For clority, I use the term combinations of control to indicate organizational attempts to employ two or more modes at the same time.

A further key assumption of my analysis is that while many modes of control can be in operation simultaneously within an organization, they vary in the degree of their coherence. In this section I explain the dimension of coherence to conceptualize the idea that a worker may experience combinations of control as either inconsistent and fragmented or consistent and unified. Coherence describes the degree of alignment between the various work goals and processes a worker perceives as being prompted by each mode of control in operation. A high degree of coherence occurs when a worker experiences combinations of control as unified and operating in concert, prompting a set of processes that collectively progress toward a shared goal. This means that it would be difficult for a worker to achieve an organizationally desired outcome by adhering to one mode of control without also adhering to another. Team working, as a mode of control, can be highly coherent with a bureaucratic mode of control when both modes encourage actions that consistently support the same goal or outcome. Take, for example, an organization that stipulates that its factory workers' individual earnings are dependent on their team's output each week. This would be likely to encourage both consistent teamwork and adherence to bureaucratic rules of production, if workers sought to achieve the goals for organizational output (see Ezzamel \& Willmott, 1998). In contrast, workers may view some modes of control as incoherent when they are fragmented and appear to serve contradictory or different purposes. In this way, the alignment of goals and processes informs how workers experience combinations of control.

The dimension of coherence should not be understood in terms of logic but in terms of contextuclized perception. As Durkheim (2008/1915) pointed out, the idea of contradiction depends on social conditions. Thus, what may appear to an outsider to be a logical contradiction is not necessarily perceived or felt as such by those who work within organizations (Landecker, 1951: 334; Willmott, 2011).

The dimension of coherence responds to calls for contextualized and nuanced explorations of the interfaces between modes of control to avoid the oversimplified notion of singular strategies and responses (Alvesson \& Körreman, 2004; Callaghan \& Thompson, 2001; Ferner, 2000). In the following subsections I examine studies of control to analyze how workers can perceive particular modes of control as coherent or incoherent. In doing so I elaborate on the key conceptual 
dimension of coherence that will underpin the theoretical framework.

\section{Coherent Control: Unified}

Reed (2011) has noted that organizations are increasingly incorporating different elements of control, rather than relying on a single mode. These "new forms promise more integrated ('joined up') forms of governing" (Harris, 2011: 107). For example, while rational and socioideological modes of control may be conceptually distinct, they are often empirically intertwined (Ouchi, 1979). Indeed, some scholars have critiqued the tendency of some scholarship to counterpose modes of control (Du Gay, 2000).

In recent work scholars have begun to empirically explore the interfaces between modes of control in contemporary workplaces (Alvesson \& Kärreman, 2004; Körreman \& Alvesson, 2004). For example, Alvesson and Kärreman (2004) studied management consultants working for Global Consulting, the Nordic subsidiary of a global professional service firm. Within Global Consulting, bureaucratic rules with various output measurement systems (e.g., balanced scorecards) provide strictly formalized performance evaluations that inform workers' salary and career development. In the perception of workers, these systems measure and rewardand thus are unified with-Global's key shared values of autonomy and meritocracy. Other critical studies of consulting firms have revealed similarly tightly coupled modes of control (e.g., Gill, 2015), with one demonstrating how a worker's low adherence to normative control led to their dismissal through bureaucratic mechanisms (Grugulis, Dundon, \& Wilkinson, 2000). In this way, coherent control modes reinforce one another, and being a committed worker requires commitment to multiple modes of control. Coherence is therefore an important dimension to consider, since it acknowledges that there can be opportunities for or constraints against workers ignoring features of control combinations.

\section{Incoherent Control: Fragmented}

Coherence is often challenging to achieve and sustain. Empirical studies of organizations that have sought to combine different modes of control, with the aim of reaping the rewards associated with each, have cast doubt on the ease with which they can blend modes seamlessly together (Hodgson, 2004). As Reed noted, modes of control can be "difficult to combine, much less integrate, into cohesive 'control regimes"' (2010: 56). Other scholars have also painted bureaucratic and normative controls as difficult to cohere to for both employers and employees (e.g., Jaeger \& Baliga, 1985).

The extant literature suggests three reasons why workers may perceive multiple modes of control used in organizations as fragmented or separated. The first is a failure of workers, including managers, to fully embrace or enforce new modes of control. For instance, senior managers may implement a normative mode of control, such as team decision making, but revert to more traditional bureaucratic measures when facing extreme or difficult problems (McLoughlin et al., 2005). This may lead workers to view a particular form of control as easy to ignore or superfluous, as in mock bureaucracies (Gouldner, 1954) or superficial cultures (Collinson, 1992). The second reason is ambiguity or uncertainty regarding the connection between modes of control. Workers may be unclear about when to adhere to one of multiple modes of control in operation-for example, when new organizational values are implemented (Colville, Dalton, \& Tomkins, 1993). A third reason is that workers may perceive contradictions between modes, such as when professional norms compete with organizationally prescribed values (Bolton, 2004). In this instance, workers may believe that it is impossible to adhere to multiple modes of control.

While the above corpus of scholarship recognizes that organizations seek to employ multiple modes of control that may be coherent to varying degrees, their interactive effects have been much less explored (Ferner, 2000). Indeed, if varying degrees of coherence can prompt different "dynamic interactions" between modes (Reed, 2011: 237), then differently coherent combinations of control can give rise to a complex array of control forms. Each form may prompt very different experiences-in terms of fulfillment or suffering - from those ascribed to single modes of control. I suggest, therefore, that the conceptual dimension of coherence plays an important role in explaining how workers' experiences of the interactive effects of control combinations may unfold. 


\section{A FRAMEWORK OF IDEAL TYPES OF INTERACTION: WORKERS' INTENSITIES OF CONFORMANCE AND RESISTANCE}

The dimensions of compatibility and coherence can serve as the axes of a framework for understanding workers' diverse responses to multiple and interacting modes of organizational control. Figure 1 displays this framework to highlight four ideal types of interaction: complementing, coexisting, competing, and clashing. In this section I theorize about the emergence, underlying processes, and implications of these different ideal types.

Both compatibility and coherence are dimensions. As a result, there is not a simple dichotomy of compatible versus incompatible or coherent versus incoherent. While workers' experiences of interacting modes of control may be most prominently characterized as compatible and fulfilling, they are still likely to encounter some difficulties and discomfort. Similarly, workers may still perceive slight gaps between highly coherent combinations of control (Hyman, 1987).

As I have stressed, these two continuous dimensions are rooted in a worker's subjective experience and perception and, thus, will be informed by a specific context in which they are embedded (Jenkins \& Delbridge, 2013). Relatedly, when describing a specific organization, I refer to $\alpha$ context rather than the context to emphasize the "potential for different actors to construct contexts via their discursive engagements which are mediated by personal cognitions and interests" (Delbridge \& Ezzomel, 2005: 608). As Storey pointed out, variations in the effects of control emerge because of "the complex interplay between more localized structural and contextual factors" as well as the "additional factor of the subjective meanings and interpretations of the participants [workers]" (1980: 148). The efficacy of any mode of control cannot be understood outside of wider economic structures (Thompson \& van den Broek, 2010) since workers' experiences-and management's choices-of strategies of control are influenced by the prevailing market conditions (Burawoy, 1979; Friedman, 1977b).

Given the importance of such contextual considerations, I illuminate the dynamics of each ideal type through the illustration of a particular empirical example. These examples are analyzed in terms of the dimensions of compatibility and coherence, and they serve to draw comparisons between the ideal types and bring to the fore how

FIGURE 1

A Framework of Ideal Types of Interaction Between Modes of Control

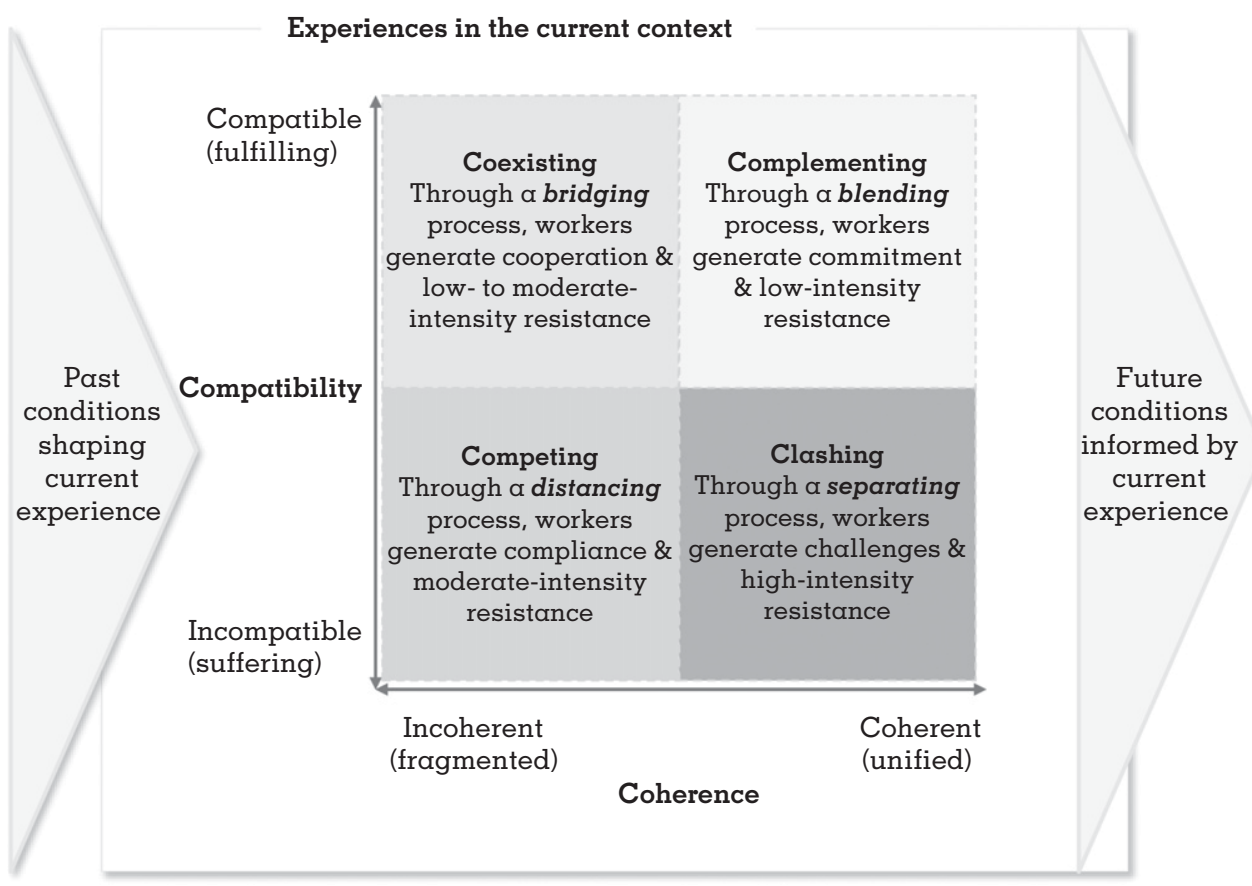


different and interacting contextual dynamics account for the experiences and reactions of workers. This focus on individual cases prevents disjointed considerations of context where contextual features are studied in isolation from each other (Johns, 2006; Willmott, 1997).

\section{Complementing Interactions}

Complementary combinations of control rely on high degrees of both compatibility and coherence. High compatibility suggests that workers experience the interactions between modes of control as beneficial, serving as a source of dignity and engendering a positive sense of self. High coherence suggests that workers experience combinations of control as operating as a unified whole, reinforcing one another. These experiences trigger $a$ key process of blending, whereby workers blend aspects of their selfhood with the modes of control, weaving them together tightly in such a way that their connection maintains a sense of fulfillment. Through this process, workers embrace organizational control and so offer commitment and limited resistance.

Barker's (1993, 1999) ethnographic study of ISE Communications from 1990 to 1992 provides a useful case to illuminate the dynamics of complementing interactions. Located in the United States, ISE Communications employs 150 workers-a cross-section of the local workingclass community - to manufacture electronic circuit boards for the telecommunications industry. Originally, the organization was a division of a large communications corporation, which sold the company to ISE management in the 1980s. Because of intense competition and threats to the organization's survival, ISE's manufacturing vice president implemented selfmanaging teams in 1988. He allowed each team to make its own decisions, as long as they were in line with ISE's values of responsibility for company performance. The foundations of the concertive (normative) discipline of teamwork emerged through the discussions of $a$ core group of workers who had "developed a consensus about what values were important to them, what allowed them to do their work and what gave them pride" (Barker, 1999: 76). Over time, the team workers created bureaucratic and rigid rules that corresponded to their normative work ethic.

Many of the ISE workers viewed the combination of controls that emerged as highly compatible.
Indeed, "members' human dignity became invested in submitting to [this] authority" (Barker, 1993: 436). Workers' culturally and historically conditioned sense of self-identity played a profound role in this process (Knights \& Willmott, 1989). For example, ISE workers faced on "irresistible force" to identify with a team identity, built on consensually constructed values of fairness and equity that were taught at an early age to be "right" (Barker, 1999: 129). Teamwork therefore offered a meaningful feeling of solidarity that justified being a "hard ass," in line with the bureaucratic rules. Several workers noted that teamwork was stressful and made demands on their individual identities. Yet, as Barker noted in his 1999 book: "They do not want to give it up. After all, this is a discipline of their creation. Their dignity, their sense of self is invested in its success" (1999: 163-164). In this way, we begin to see why workers sought to blend with and maintain a personal investment in the combination of control. When Barker asked one worker why she kept coming back, she responded, "You feel successful when your team is successful" (1999: 164).

The ISE team members appeared to experience the modes of bureaucratic and normative control as highly coherent. The workers' construction of bureaucratic and rigid rules reinforced the normative control by making it more easily understandable, rewardable, and punishable. This indicates how the workers blended themselves with the two modes of control in practical terms, by providing and adhering to clear guidance on what was required to be a team member. Thus, control wound "tighter and tighter amongst them" to "compel their willful obedience" (Barker, 1999: 164).

In viewing conformance as a source of "human dignity" (Barker, 1993: 425), "for the most part, the issue [of resistance] was never one the workers really considered" (Barker, 1999: 114-115). Instead, their commitment and work ethic took on a "heightened intensity as their concertive discipline became more heightened and refined" (1999: 78). Workers actively embraced the combined controls by blending them with their sense of self. This intensified worker commitment and penalized dissension. This was the case for Joey, "a temporary who worked hard but had a tendency to wander off across the shop and socialize" in defiance of established norms, leading to his dismissal by fellow team members (Barker, 1993: 427). As Driver (2002) pointed out, when workers fulfill 
their own developmental needs and cooperate for a common purpose, which they perceive as being for their own good, this may itself be the most powerful control mechanism (see also Jermier, 1998).

\section{Coexisting Interactions}

Coexisting combinations of control have a high degree of compatibility and a low degree of coherence. Coexistence reflects the idea that different modes of control can operate in parallel or can assume dominance at different times (Orlikowski, 1991; Storey, 1985). This means that while two or more modes of control may facilitate some sense of fulfillment, their beneficial properties are not fully realized because employees experience these modes of control as somewhat incoherent. These experiences can trigger $a$ bridging process, as workers seek to connect with or become more closely involved with modes of control they find fulfilling. Resistance is likely to incorporate a constructive and generative form, often appearing as cooperation, with workers seeking to engage with the combinations of control that afford them a sense of fulfillment.

This ideal type of interaction can be seen in the work of McLoughlin et al. (2005), who conducted fieldwork on a 600-employee traditional cokemaking plant ("CokemakingOz") from 2000 to 2001. CokemakingOz's core task was reforming coal into coke. The plant was a dusty, dirty, and unpleasant place for workers, and its workplace culture had historically been one of "low selfesteem (it had commonly been seen as 'the arse end' of the company's operations)" (McLoughlin et al., 2005: 73). Workers resented management's privileges, such as a "staff" and "wages" toilet, which stemmed from a traditional bureaucratic and hierarchical structure. Against this backdrop and increasing competition from the Chinese steel industry, a new manager was tasked with implementing cultural change in 2000. This focused on creating a collective workforce vision. A work redesign process involved a managementemployee cross-functional working party to develop a "blueprint" for new working practices and culture (McLoughlin et al., 2005).

In terms of the workers' experiences of compatibility, the new form of normative control-in the form of participatory team work-appeared to provide a source of fulfillment for many employees. This reflected the increased autonomy that this new form of control afforded. As a worker remarked, "We had our chance to have a say" and to give voice to issues and concerns (McLoughlin et al., 2005: 82). The working party was an open forum, where all employees could be involved. The party's remit extended well beyond changes to production and encompassed culture change. The working party's meeting culminated with the publication of a new blueprint ("The Coke Guide"). In an effort to bridge bureaucratic and normative controls, 60 percent of workers voted to indicate their acceptance of the proposed measures directly affecting their work area, which the plant manager then implemented. The result was an overall improvement in working attitudes, according to two company surveys.

In terms of the dimension of coherence, the traditional bureaucratic modes of control often became loosely bound up with the new participative and normative mode of team working. Unlike Barker's (1993) ISE managers, who felt compelled to support work team decisions, CokemakingOz managers were "not immune from departing from the 'value-led normative control' script" (McLoughlin et al., 2005: 77). For instance, when a worker behaved violently and damaged property, a manager left the team to resolve the issue over a weekend, which was "consistent with the new rhetoric of empowerment" (2005: 77). He then changed his mind and, after due deliberation, fired the worker concerned. As the authors noted, the conventional tools of bureaucratic controls got the better of this manager. In an ultimately successful attempt to bridge bureaucratic and normative controls, the workers took part in a stoppage of work, the first at the plant following eighteen months of relative industrial peace.

Workers' resistance in CokemakingOz stemmed from this process of bridging. The bridging process could occur through official means, such as a vote, as well as unofficially, as in the first instance of a stoppage at the plant following the implementation of participative teams. While such a stoppage is often viewed as a purely oppositional form of resistance, in this instance it was also constructive, as workers sought to enforce the additional mode of normative control encouraged by management. Such resistance, in its various forms, is therefore not only "oppositional" but also "generative." Workers do not simply react to control but "exploit the looseness around meanings in a constant and simultaneous 
process of resistance, reproduction and reinscription" (Thomas \& Davies, 2005: 699; see also Meriläinen, Tienari, Thomas, \& Davies, 2004). Workers' experiences of coexisting interactions can trigger a process of bridging, where they seek to close the gaps between incoherent modes of control to embrace additional modes of control that offer a sense of fulfillment.

\section{Competing Interactions}

Competing combinations of control are characterized by a low degree of compatibility and a low degree of coherence. Low compatibility means that workers experience modes of control as aggravating or prompting suffering when they interact. Low coherence reflects workers' perception that two or more modes of control are incoherent-or often rife with contradictions-in their everyday work. This is similar to what Storey (1980, 1985) described as "competing logics" to the different modes of control. These experiences trigger the process of distancing, through which workers seek to distance or keep at bay contradictory modes of control. This allows workers to evade or limit the suffering stemming from their combination. This can prompt more moderate intensities of resistance, because the gaps or spaces that exist between fragmented modes of control provide openings for workers to exercise choices over which aspects of control they experience.

An example of this is Bolton's (2004) study of gynecology nurses between 1994 and 2000 within the U.K.'s National Health Service, at Bolsover Hospital. Beginning in 1994, Bolsover introduced many bureaucratic policies associated with management in the private sector, such as target setting, performance appraisals, quality audits, and sickness monitoring (Bolton, 2004). Senior management sought to "change hospital culture to one of customer care and quality consciousness, where hospital employees are empowered to deliver a superior service" (Bolton, 2004: 326). This was reflected in mission statements, customer satisfaction surveys, and brochures advertising the hospital's attempts to empower staff to focus on the needs of health care "consumers."

In terms of compatibility, the nurses found the sustained emphasis on patients as consumers to be a source of suffering. Beyond nurses' complaints that some days their faces ached with the effort of maintaining the required "smiley face," the customer focus threatened the value-laden nature of their work as a vocation, which rested on a moral obligation to be patient advocates and to provide the best possible care for patients. As one nurse described it, "We are the patient's advocate. ... when we stop being the patient's advocate we also stop being nurses" (Bolton, 2004: 328) Nurses' professional identity is bound up in the history of their profession (Abbott \& Wallace, 1990). Threats to this important sense of self were therefore troubling for many nurses. This helps to explain why some nurses would seek to distance the new consumer focus from their traditional professional values.

In terms of coherence, many nurses often kept the bureaucratic and cultural control mechanisms distinct from their preexisting normative conventions of nursing as a vocation. While nurses appeared to comply with what they described as "patient as King" in their interaction with some "consumers," there were clear limits to this, and, as one nurse explained, "It's crap and I, for one, can't see the point" (Bolton, 2004: 329). With few mechanisms to enforce "appropriate" behavior, nurses did not always perform dutifully when interacting with patients. They made it clear that their performances were often cynical and merely a surface act (Fleming \& Spicer, 2003; Hochschild, 1983), and not displays of genuine concern for "consumers." In so doing, they distanced themselves from managerial attempts to encourage a belief in nursing as a consumer service, thereby safeguarding their professional values.

Stemming from the process of distancing, many of the nurses' acts of resistance were moderate in intensity. Although the nurses' resistance did not seek overtly to challenge the new modes of hospital control, they found their acts to be meaningful. This becomes clearer in context, since the professional association for nurses-the Royal College of Nursing-had not supported industrial action or strikes historically (Jennings \& Western, 1997). Nurses in Bolsover Hospital noted how they achieved some sense of control and pleasure from "taking the piss" out of their "consumers." One nurse stated, "Some days I just can't be bothered with this 'patient as customer' business. What a load of rubbish it is. I go to extraordinary lengths to avoid having to be nice to them when they're getting up my nose" (Bolton, 2004: 329). I suggest that the spaces between incoherent modes of control provide openings for workers to exercise 
choices over the aspects of control they experience. This allows them to distance themselves from their source of suffering in various ways, thereby tempering the intensity of their resistance.

\section{Clashing Interactions}

Clashing combinations of control are characterized by a low degree of compatibility and a high degree of coherence. Low compatibility suggests that workers experience suffering from combined modes of control. High coherence suggests that workers experience combinations of control as operating as a unified whole and, often, inescapably connected within the workplace. These experiences trigger a separating process, where workers seek to remove or separate themselves from the combination of control that aggravates or adds to their suffering. This process can therefore prompt workers to reflect on and demonstrate high-intensity resistance.

To illuminate some of the dynamics at play within the competing ideal type, I draw on Ezzamel and Willmott's study of machinists in StitchCo factories between 1992 and 1996. Formed over sixty years ago as a U.K. family-owned company, StitchCo had grown from being a "kitchen-table" manufacturer of dress wear to occupying a distinctive niche in the garments market. The organization was successfully listed on the London Stock Exchange in the late 1980s but came close to receivership within two years as profits declined, which was due in part to an extended financial crisis. In a bid to restore profitability, management sought improvements in flexibility and response speeds to fluctuating demand through the phased replacement of line work by teamwork in the early 1990s. When a breakdown occurred under the traditional line work system, the established custom was to compensate individual machinists for delays with an average of what they had earned over the past eight weeks. There was therefore no incentive for machinists to avoid or rectify breakdowns quickly. Managers' implementation of teamwork sought to address this issue by making workers responsible for one another, but with little input from the workers themselves (Ezzamel \& Willmott, 1998: 369-379).

In terms of compatibility, many of the StitchCo workers found the addition of the normative and team-based control to be a source of suffering.
This was an unintended consequence of managers' decisions, since they believed that teamwork would free workers from a line work system they viewed as "dehumanizing and degrading as well as inflexible and inefficient" (Ezzamel \& Willmott, 1998: 388). In many cases, however, particularly for low performers, "Members of each group tended to regard the interdependence of teamwork as a burden, not as a benefit" (1998: 387). Teamwork and shared accountability risked workers' highly valued relationships with one another, as well as their self-identity as "mates." These friendships were threatened since earning a wage equivalent to line work required either the continuous cajoling of other teammates or working harder to compensate for them. As one of the machinists explained, "I prefer line work and piecework rather than group work ... If you're having a bad day, then you only get paid by the amount of work you do and the other girls don't suffer" (Ezzamel \& Willmott, 1998: 381).

Thus, the implementation of teamwork threatened workers' investment in prized practices, such as line work, and values, such as friendship. This loss was not offset by identification with consensually created team values, as it was in Barker's (1993) ISE Communications. Instead, in StitchCo there was a "belief that teams would identify with the financial indicators used to assess their performance" (Ezzamel \& Willmott, 1998: 377). Workers had new ways of working thrust upon them, with little input into the introduction of autonomy. This was also likely to inform some of their low levels of compatibility because, as Burawoy (1979) noted, the human desire for autonomy is strong and can be unfulfilled when workers are treated as the mere recipients of managerial instructions. This serves to clarify why workers would seek to separate themselves from a combination of control they perceived as hormful.

In terms of the dimension of coherence, teamwork as a mode of control was tightly integrated into the operations of the organization; individual earnings were made partially dependent on team performance. Work was reorganized using teams comprising six operators selected by management. Each team of machinist workers, for example, had two with lower skill levels, two with medium skill levels, and two with high skill levels (Ezzamel \& Willmott, 1998). The team bonus system was intended to provide an incentive for team members to cooperate with each other to 
maximize their production. In this way, it was difficult for many of the machinists to evade the expectations of teamwork, because "the team rather than the individual became the primary unit of accountability for delivery of performance and quality to which bonus payments were tied" (Ezzamel \& Willmott, 1998: 375).

The implementation of teamwork thus prompted suffering and fomented hostility toward the managerial goal of making the teams fully selfmanaging. The result was that many workers attempted to separate themselves from the combination of control. Given the nature of their work, workers' attempts to separate themselves from these controls was overt and manifested in taking extra breaks or being unresponsive or even antagonistic to management directives. I describe this as high intensity since workers would openly resist the discipline of self-managed teams, even though this could threaten their wages and their valued social relationships with fellow workers. The result was that the StitchCo managers were obliged to accommodate the machinists' resistance, providing further external supervision to manage interpersonal conflicts between machinists. This led to the contradictory consequence of undermining moves to establish selfmanaging teams, thereby strengthening management (Cressey \& MacInnes, 1980; Ezzamel \& Willmott, 1998). Clashing interactions constrain workers' choices in escaping suffering, which can trigger a separating process that prompts more intense forms of resistance.

\section{BOUNDARY CONDITIONS AND LIMITATIONS OF THE FRAMEWORK}

Identifying key assumptions and boundary conditions is important when building theories that require the mapping of concepts and processes (Okhuysen \& Bonardi, 2011). A key premise of the framework presented here is that workers can experience interactions between modes of organizational control. The framework advances the dimensions of compatibility and coherence as two important considerations that help to explain how workers can experience these interactions. Workers' experiences are shaped by the dynamic sociocultural, geographic, and temporal context in which they are embedded (Jenkins \& Delbridge, 2013), as well as their subjective experiences (Knights \& Willmott, 1989). The fromework therefore also stresses the dynamic and recursive relationship among control, resistance, and the wider environment (Edwards, 1979; Giddens, 1984). I do not suggest that the experience of suffering will necessarily provoke resistance (Lawrence \& Robinson, 2007) or that suffering is the sole source of resistance. Nor does resistonce necessarily alter the nature of control. It may have the unintended consequence of reproducing dominant forms of power (Burawoy, 1979; Mumby, 2005), since to resist something also means to reify it by privileging it as a meaningful focus of contestation (Thomas \& Davies, 2005).

To illustrate how modes of control interact in terms of the degrees of coherence and compatibility, I have argued that it is conceptually useful to treat each ideal type of interaction (i.e., complementing, coexisting, competing, and clashing) as distinct. An inevitable consequence of categorization and classification is some degree of simplification (McKinney, 1969; Voronov \& Vince, 2012). Nonetheless, I recognize that differences exist within each analytical category. The focus on specific examples serves to emphasize the complexity of how workers experience control, whereby different workers within the same organization can be situated at different points along each dimension (see also Zanoni \& Janssens, 2007).

Following on from this, while the framework presents ideal types as mutually exclusive to provide analytical categorizations, any categorization is a snapshot in time. Ideal types "crystallize hypothesized elements of empirical instances and, by their nature, are static constructs" (Biggart \& Delbridge, 2004: 44). As the empirical examples used to explore each ideal type indicate, the experience of control is temporally dynamic, and workers' experiences of control modes within a single organization can be categorized into multiple ideal types over time. While modes of control can evolve (Cardinal, Sitkin, \& Long, 2004), so, too, can workers' experiences. For example, empirical studies highlight how, in recent years, many public service organizations in the United Kingdom have witnessed a proliferation of new forms of control, leaving workers increasingly cynical regarding new initiatives (Thomas \& Davies, 2005). Conversely, a worker's experience of compatibility may be enhanced over time, such as when normative control successfully persuades a worker (Hennart, 1993) or manufactures the worker's values to align with the espoused corporate position (Alvesson \& Willmott, 2002). As a 
result, previous experiences will inform workers' projections into the future. Commitment and resistance can therefore be viewed as provisional (Morris, Lydka, \& O'Creevy, 1993), since workers' sense of self resists definitive closure (Brown, 2006). The previous empirical illustrations of the framework's ideal types only capture the interactions in particular periods and represent temporary outcomes (Storey, 1985). As Willmott (2011) noted regarding Weber's (1978) ideal type of bureaucracy, actual forms rarely, if ever, correspond to any ideal type but, rather, constitute combinations and mixtures over time. Yet they remain valuable conceptual tools for analysis and understanding.

In a socially constructed world, abstract frameworks serve as maps to understand and examine complex topics. Nonetheless, a "map is not the territory it represents, but ... has a similar structure to the territory, which accounts for its usefulness" (Korzybski, 1958: 58). As such, I proffer the framework as a roadmap to future research and as a way to generate discussion on complex issues of similarity and difference. The value of abstractions, as Weick (1989) pointed out, is not just that they can serve as maps that provide labels or categorizations but that they can prefigure action and perception. This can have a negative effect, such as when people or phenomena are narrowly categorized in a way that reduces their complex and dynamic nature, which can be used to limit choices (as discussed by Thomas, Hardy, Cutcher, \& Ainsworth, 2014). Abstraction can, however, be positive and valuable by providing new vantage points to understand organizations and those who work within them (Delbridge \& Sallaz, 2015) and by illuminating many of the processes that underpin control and resistance. For example, the four ideal types reflect the interests of critical scholarship, encouraging greater attention to how and why workers suffer and, thus, supporting the possibility of emancipatory and remedial action.

\section{DISCUSSION AND FUTURE RESEARCH DIRECTIONS}

I have developed a framework that explains workers' diverse responses to combinations of organizational control. I contend that these responses are informed by the degree to which workers experience modes of control as coherent with one another and as compatible with aspects of their personhood that they deem important. Through empirical examples I have illuminated how ideal types of interaction can emerge in certain instances and how workers experience them. These particular experiences can trigger specific processes-blending, bridging, distancing, and separating - that help to explain why the same two modes of control can yield contradictory outcomes in terms of compliance and resistance in different settings. In the following subsections I specify how this framework builds on and contributes to research on control, resistance, and suffering in organizations. I also discuss future research directions associated with each contribution.

\section{Control Interactions and Their Interactive Effects}

The framework explicitly draws together critical management scholars' recognition of the importance of workers' subjectivities (Ezzamel et al., 2001; Knights \& Willmott, 1989; O'Doherty \& Willmott, 2001) and growing interest in multiple modes of control and their interactive effects (Alvesson \& Körreman, 2004; Ferner, 2000; Reed, 2010). I build on these topics by proposing and outlining four ideal types of interaction between multiple modes of control that workers can experience. As demonstrated in the taxonomy (Table 1), these ideal types provide a way to conceptualize and categorize studies that have examined workers' experiences and responses to similar combinations of control modes in different contexts and at different times (the four exemplar studies are marked with an asterisk). The framework thereby offers a lens through which to better understand the complexity of contemporary control.

The proposed ideal types and associated processes help to reconcile several divergent findings across different streams of critical research. The studies in Table 1 provide further evidence that each ideal type of interaction is associated with different processes that prompt distinct intensities of conformance or resistance.

For instance, the process of blending in complementing ideal types of interaction explains why workers can offer high levels of commitment and consent (Burawoy, 1979). As workers blend aspects of their selfhood with the modes of control to make them highly compatible, adherence to these control modes maintains a sense of fulfillment. This blending can occur as workers 


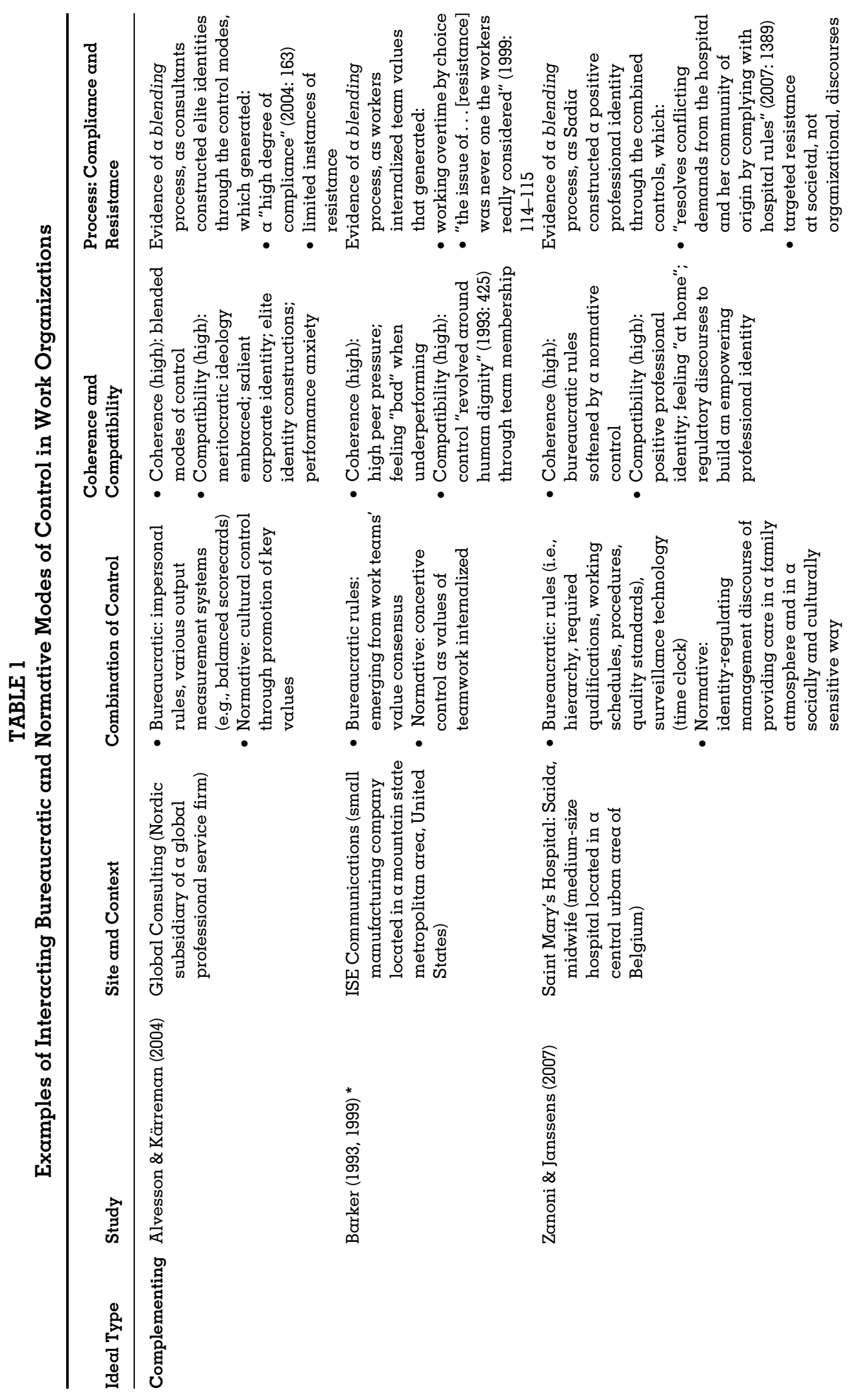



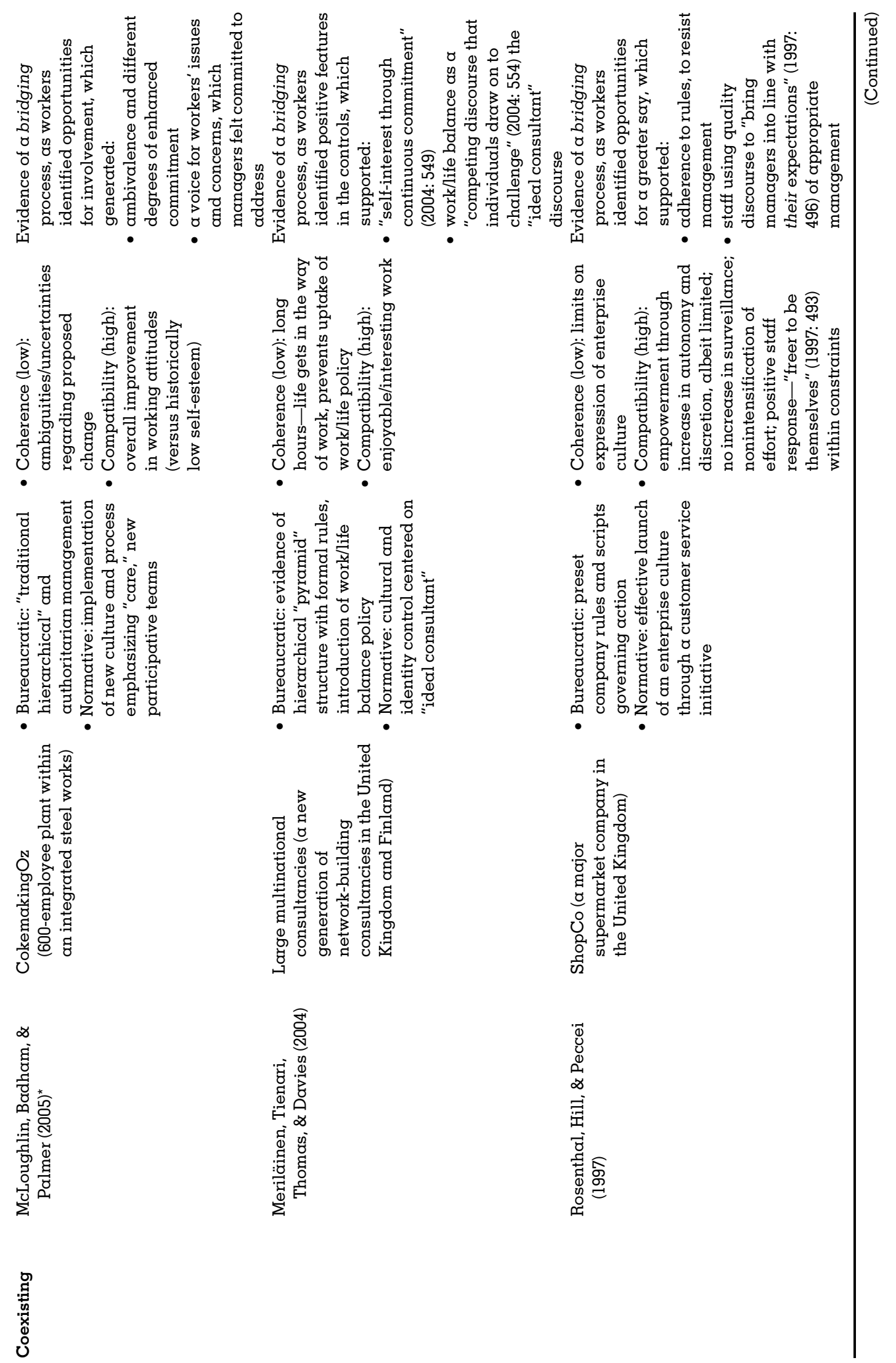


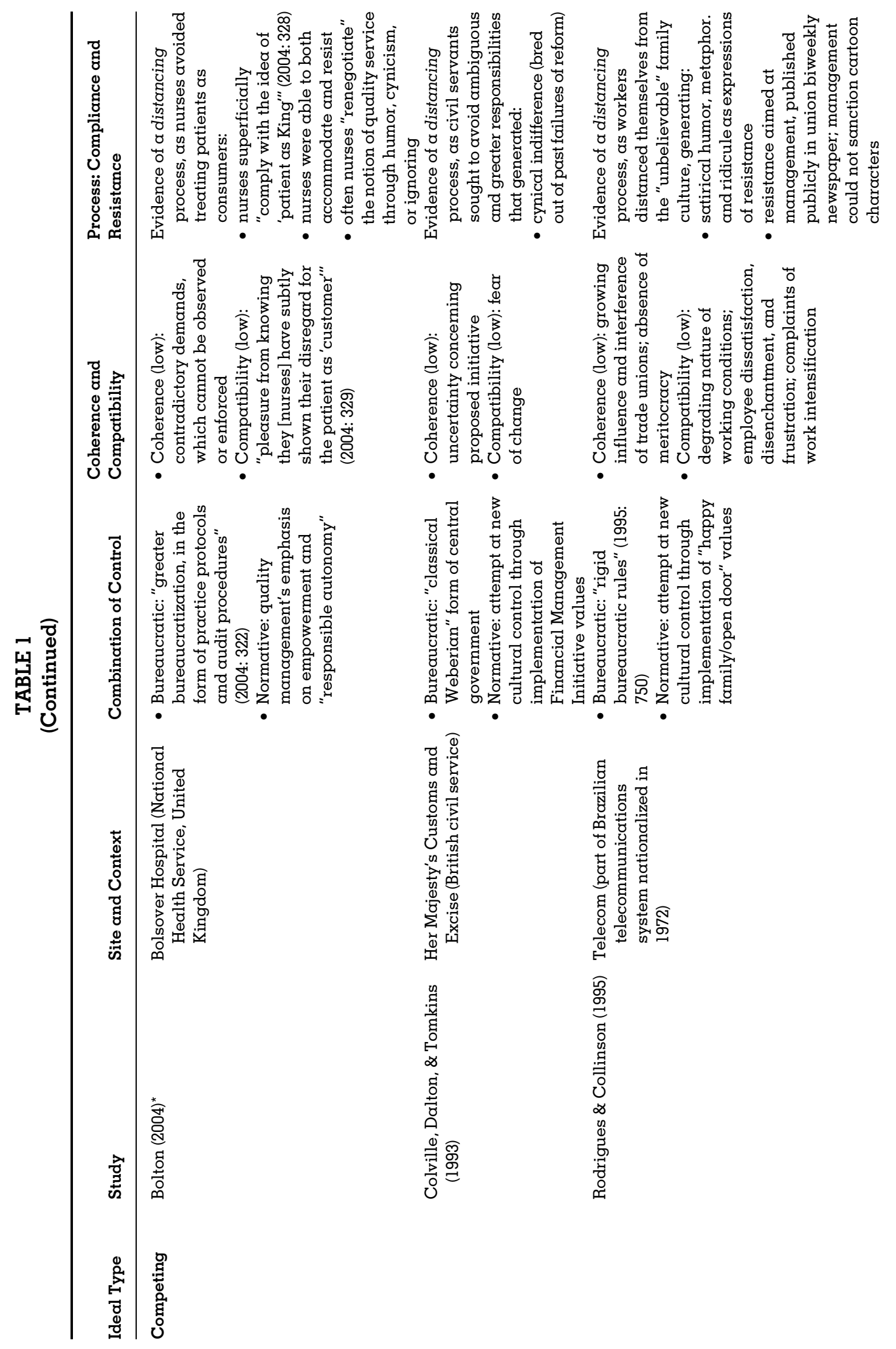




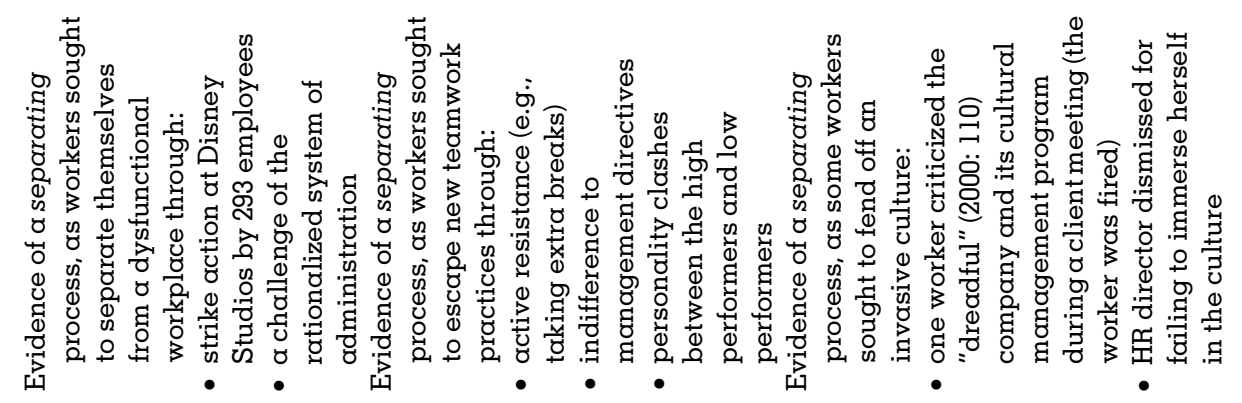

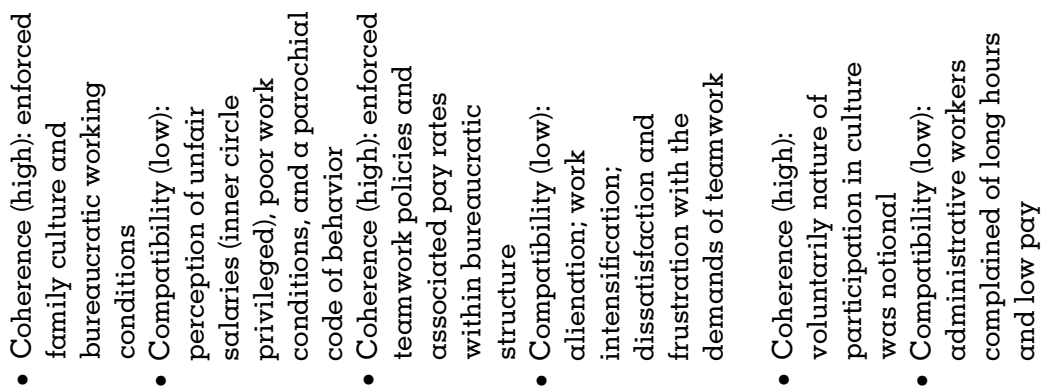
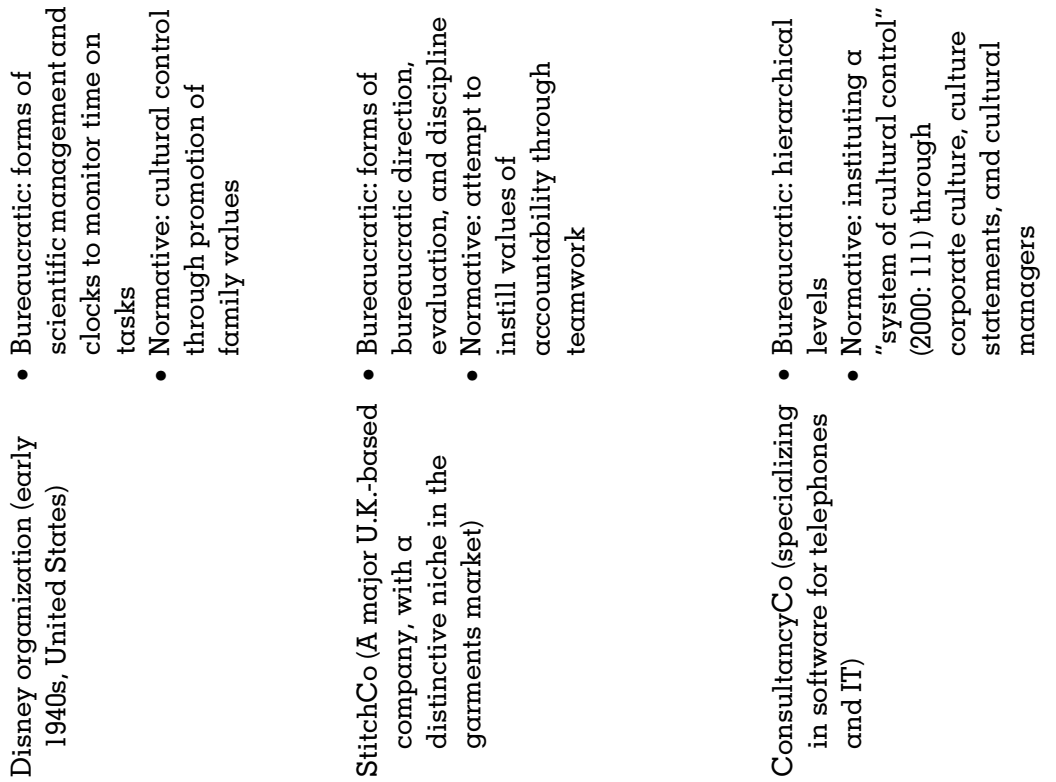

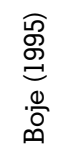

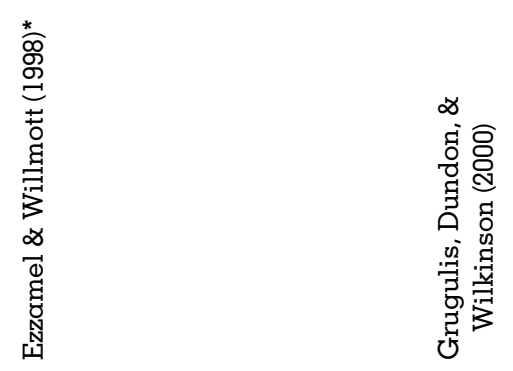

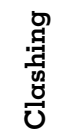


internalize core values, as in Barker's (1999) study of ISE Communications. It may also happen when workers construct highly valued identities through the control modes (Alvesson \& Körreman, 2004; Zanoni \& Janssens, 2007). Workers may willingly reproduce and police modes of control that "are deemed by them to be more compatible with self-identity" (Willmott, 1993: 546) and that align with their other salient sources of identity formation and affirmation (Alvesson \& Willmott, 2002; Thomas, 2009). When highly valued aspects of a worker's personhood, typically their sense of self, are closely bound up with control modes, then their commitment to these modes of control is likely to be high.

The bridging process in coexisting types of interaction offers an explanation for why workers can perform simultaneously constructive and disruptive resistance (Thomas \& Davies, 2005). Beyond the overt worker stoppage that McLoughlin et al. (2005) identified, bridging may also take different forms, as demonstrated in a study of workers' experiences of coexisting interactions in a retail organization. In this case employees "felt that they could use the language of the ... [new program that provided them with greater autonomy] to express their displeasure with management and the company" (Rosenthal, Hill, \& Peccei, 1997: 496). This is similar to what Collinson (1994) described as resistance through persistence, through greater involvement to hold management accountable. Workers can therefore welcome and seek to incorporate additional modes of control that they perceive as a source of more fulfilling work.

The distancing process in competing types of interaction explains why workers con pursue moderately intense oppositional resistance (Fleming \& Spicer, 2003). Bolton's (2004) identification of nurses' attempts to mock and ignore a new consumer culture is similar to Rodrigues and Collinson's (1995: 755) study of a Brazilian firm, where managers' superficial rhetoric of participation served to aggravate current experiences of an autocratic environment. Workers reacted by distancing themselves from these new policies through satirical humor, ridicule, and irony that drew a clear distinction between control modes. This corroborates much of the existing literature, which suggests that contradictory or inconsistent control practices can be a precursor to employee resistance (Burawoy, 1979; Gagnon \& Collinson, 2017). As I have argued, however, the low coherence between these modes of control provides spaces for workers to evade the control, thereby tempering the intensity of their suffering and their need for resistance.

The separating process in clashing types of interactions helps to explain the emergence of traditional notions of antagonistic worker resistance and contestation (Edwards, 1979). In Ezzamel and Willmott's (1998) study of StitchCo, workers feared the loss of prized practices and social bonds (see also Grey \& Sturdy, 2007, and Knights \& McCabe, 2000). Threats to self-identity can be a powerful source of suffering (Ezzamel et al., 2001) that, I contend, can trigger workers to separate themselves from the aggravating control modes through intense resistance. This is borne out by scholarship (Hodson, 1991; Mars, 1982) suggesting that when workers are overconstrained by rules they cannot evade, and find their needs are unmet, they are more likely to pursue forms of resistance to "get even." Such intense responses, albeit in a variety of forms, have been identified in settings where workers have experienced similar degrees of high coherence and low compatibility. For instance, there are pockets of employees who will actively and publicly speak out against their organization or resist through nonparticipation in the culture (Grugulis et al., 2000) or through formal strikes (Boje, 1995), while risking redundancy.

In recognition that changes in context and subjectivities can encourage workers to oscillate between ideal types, the framework's dimensions provide several related opportunities for further research to explicate why and when workers are likely to pursue differing response processes over time. For example, are there salient contextual factors that increase the likelihood that workers will experience a certain ideal type? How and why do workers' experiences shift from one ideal type to another? The previous empirical examples explored through the framework have begun to highlight certain contextual factors, in specific settings, that are significant in informing or mediating workers' experiences of compatibility and cohesion-for example, peer relationships (Ezzamel \& Willmott, 1998), professional values (Bolton, 2004), and social values (Barker, 1993). There are likely to be many other factors that are meaningful to workers and that could be examined in terms of each ideal type, such as labor market conditions and the material rewards of work (Eisenhardt, 1985; Mitchell \& Mickel, 1999). For instance, university employees in the United Kingdom recently 
went on strike in response to proposed changes to radically restructure their pensions (Adams, 2018).

One specific direction for future research is to examine different underlying values at both the corporate and national level. Extant research suggests that the corporate values and objectives underlying normative modes of control will mediate workers' experiences (Alvesson \& Willmott, 2002). For example, several studies have demonstrated how workers' identification with a corporate value of elitism help to enhance commitment to normative modes of control and minimize tensions between control and autonomy (Gill, 2015; Kärreman \& Alvesson, 2004; Robertson \& Swan, 2003). In contrast, corporate values of "happy families" have been shown to prompt lower levels of compatibility and to encourage resistance (Fleming, 2005; Rodrigues \& Collinson, 1995). Further examinations of various corporate values across different settings could further illuminate their role.

In addition, underlying national values may play an important role. With the exception of Rodrigues and Collinson's (1995) study set in Brazil, all of the studies examined through the framework in this article consider North American or Western European organizations. This reflects a broader opportunity in management research for further studies across different nations outside the West (George, Corbishley, Khayesi, Haas, \& Tihanyi, 2016; Özkazanç-Pan, 2008). I suggest that values are likely to inform workers' experience of compatibility since the concept of fulfillment typically derives its meaning within a value system (Kalleberg \& Griffin, 1980). Insights stemming from empirical examinations of values may extend and refine our understanding of workers' experiences of compatibility and coherence or, potentially, identify additional or different dimensions to explain workers' responses to control.

Comparative case study research could support such examinations of the contextual factors that inform workers' experiences. Examinations across different settings would help to elaborate and refine explanations of what drives variance within and between ideal types over time. Researchers could draw inspiration from Delbridge's (1998) critical and rich case study comparison of blends of control modes. They could also draw on Eisenhardt and colleagues' multiple case study approach (Eisenhardt, 1989;
Eisenhardt \& Bourgeois, 1988). As Edwards (2010) and Thompson and van den Broek (2010) have pointed out, there is a need for more systematic comparative analysis and varied units and levels of analysis to overcome the limited capacity for generalization that has constrained much study of control and other workplace issues. Following Biggart and Delbridge, I contend that "ideal types represent a basis for comparing empirical instances of a phenomenon with a baseline" (2004: 44), and, thus, the framework aids further comparative analysis.

Further empirical work is also required to establish the relationship between the two dimensions of compatibility and coherence. The empirical studies I examined earlier suggest that both very high and very low degrees of worker compatibility are closely coupled with a high degree of coherence. Less extreme degrees of compatibility and coherence also appear to be related. In this way, the relationship between these two dimensions does not appear to be straightforward or linear. Closer attention to workers' experiences of control and resistance in terms of these two dimensions would be likely to illuminate their dynamic relationship. For instance, how and why-if at all-do shifts in workers' experiences of coherence inform their experiences of compatibility, or vice versa?

Studying interactions between different modes of control, beyond the bureaucratic and normative modes examined here, such as technical (Anteby, 2008b; Delbridge, 1998) or neonormative (Fleming, 2009), could broaden the applicability of the framework. It may be that different modes of control can interact in different ways and prompt different processes than those identified here.

A further intriguing pathway for future research stemming from the framework is a consideration of how different aspects of a worker's personhood may simultaneously exist within different ideal types. Often overlooked in existing studies are workers' unintended physical responses that constitute involuntary resistance. As a rare exception, Michel's (2011) study of highly committed bankers revealed how after several years of habitual overwork, which bankers experienced as self-chosen, many of these bankers' physical bodies broke down. The behavior of these bankers therefore altered, typically in the form of being unable to work with the same intensity, thereby resisting the demands of their organizations. There are traces of the potential for such 
embodied resistance in other studies of highly compliant workers (e.g., Casey, 1995, 1999). To a more extreme degree, often when workers appear to experience highly compatible and coherent combinations of control, there is the prospect of physical suffering in the form of karōshi, which can be translated from Japanese as death from overwork (Nishiyama \& Johnson, 1997). In some cases workers willingly sacrifice their health to sustain their self-esteem (Pfeffer, 2018). Exploring the potential of somatic resistance or subtle aspects of suffering across a highly compliant workforce is a promising avenue for further research. Longitudinal studies could examine how different aspects of workers can react to control, sometimes independently and in contradictory ways, leading to the possibility that workers may simultaneously conform and resist across different aspects of their personhood.

\section{Intensities of Resistance}

The ideal types help to reframe ongoing deliberations concerning the nature of resistance. I argue that each ideal type of interaction is associated with a process that prompts a different intensity of resistance, rather than a particular strategy or form (Ackroyd \& Thompson, 1999). I use the term intensity to draw a distinction between the manifest act of resistance (e.g., a strike, sabotage, soldiering, or cynicism) and the experience and meaning of this resistance for a worker.

As examined previously, different industries or occupations will present different forms of resistance. In certain manufacturing organizations, workers often engage in stoppages (e.g., McLoughlin et al., 2005). In contrast, the same act by a worker in a professional service firm would be likely to take on a much greater significance owing to a range of contextual factors, including historical precedents and the prominence of unions. For example, Grugulis et al.'s (2000) study of a consulting firm revealed how employees' small acts of countercultural behavior, such as criticizing their employer to clients or not fully embracing the corporate culture, led to their dismissal. In more extreme contexts, where resistance is inadvisable or even dangerous, subtle or symbolic acts might be workers' only meaningful recourse (see Scott, 1990). In this way, workers' unique contexts will induce their own expressions of resistance and potentially transformative action (Giddens, 1984; Orlikowski, 1991).
I therefore concur with the view that "resistance always needs to be understood contextually; what counts as resistance shifts with the economic, political, and socio-cultural terrain" (Mumby et al., 2017: 1173). Resistance may take a variety of subtle forms, such as subversion and forms of absenteeism or disengagement, alongside direct forms of worker recalcitrance (Collinson, 1994; Ezzamel et al., 2001; Gabriel, 2008; Jermier, Knights, \& Nord, 1994; Prasad \& Prasad, 1998). Collective or overt forms of resistance are not, however, necessarily more powerful than subtler forms. Indeed, "in certain cases the 'mental strike' or indifference of one individual ... could be more damaging to management than a strike by an entire workforce" (Edwards, Collinson, \& Della Rocca, 1995: 291). While unofficial transgressions such as cynicism and humor may often "consist of an edulcorated resistance" (Contu, 2008: 374), this is not always the case. My contention is that the meaning and power of workers' resistance become clearer when considered in terms of its contextualized intensity, which is distinct from the particular form of resistance employed.

I posit that workers' experiences along the dimensions of compatibility and coherence trigger particular processes that generate different degrees of intensity, from low to high intensity. In more practical terms, low-intensity resistance equates to workers pursuing acts of resistance that they would deem limited or superficial in challenging, denaturalizing, or scrutinizing the prevailing power structures that underpin organizational control (Mumby et al., 2017). Highintensity resistance describes workers' efforts to challenge organizational control in a way that is meaningful for them within their unique context.

The notion of intensity invites further research into more subtle or hidden expressions of disruption. Resistance may operate in collective and overt action or at the micro level of identities, across a range of intensities. Furthermore, such intensity may be multidirectional (Thomas \& Davies, 2005), being constructive and generative while also being disruptive. As I identified in the framework, through the resistance generated by the process of bridging, the overt and collective worker stoppage in McLoughlin et al.'s (2005) study of CokemakingOz's was somewhat constructive, as workers sought to enforce the additional mode of normative control encouraged by management that they found fulfilling. This complements other research that has identified 
how microlevel resistance may also be simultaneously constructive and disruptive when viewed from the perspective of workers themselves (Thomas \& Davies, 2005; Thomas, Sargent, \& Hardy, 2011). The notion of intensity therefore builds on existing resistance research by developing a framework to account for why different intensities of resistance may emerge, while respecting that the manifestations of such resistance are contextually constrained. The framework currently suggests that resistonce is more likely to be generative when workers experience control as a source of fulfillment. Future research that focuses on the lived experience of workers could elaborate on this contention.

A further possibility for future research is to examine why a certain level of intensity may come to be shared across workers within an organization. In examples of collective action, such as strikes, there appears to be a high degree of intense resistance that is widely distributed across many workers. In the prior examination of empirical studies through the fromework of ideal types, it appears that higher levels of intensity, whether in the form of commitment or resistance, are more likely to be shared when there is a high level of coherence. One explanation for this is that when multiple modes of control are highly coherent and consistently reinforce one another, there is little opportunity for workers to evade their effects, unless they pursue highintensity resistance. Future research could examine the social nature of intensity. For example, what social processes may operate to align degrees of intensity? How and through what mechanisms could social interactions increase or decrease such intensity? A potentially related stream of research to consider in this regard focuses on compassion at work (Kanov et al., 2004; Maitlis, 2009). Although rarely considering workplace resistance, these studies highlight how the feeling of witnessing another's suffering can motivate a subsequent desire to help (George, 2013). Such compassion, whether emanating from work colleagues or family, may serve to ameliorate workers' experiences of suffering, thereby tempering the intensity of their resistance.

\section{The Significance of Suffering}

A key implication of the framework is that while there remains a need to identify and be aware of unnecessary suffering (Adler et al., 2007), suffering is more than just a potential outcome of control. It is also an explanatory concept that can help to illuminate how and why processes of control and resistance unfold across settings. For instance, in Ezzamel and Willmott's (1998) study of StitchCo, workers suffered a loss of prized practices and social bonds because of the implementation of new normative controls. Their experiences help to explain why many of these workers pursued intense forms of resistance that took the form of openly challenging management and peers, taking extra breaks, and refusing to work in teams, even though this reduced their own wages. Existing scholarship has indicated how varying intensities of resistance to control have been informed by other forms of worker suffering, such as damage or threats to professional or self-identity (Bolton, 2004; Ezzamel et al., 2001) and dysfunctional or exploitive workplaces (Boje, 1995; Rodrigues \& Collinson, 1995). The concept of suffering therefore plays an important role in explaining the dynamic relationship between control and resistance across different contexts.

The desire of workers to reduce their suffering and enhance their fulfillment is also important in explaining workers' commitment to control. For instance, Barker's (1993, 1999) study of ISE Communications workers revealed how they blended aspects of their selfhood with the modes of control, weaving them together tightly in such a way that their connection maintained a sense of dignity and fulfillment. Resistance against such compatible modes of control could intensify workers' suffering as the positive interactive effects of the control modes are lessened or lost. This demonstrates why control can be so powerful, since it affords a positive sense of self or ameliorates a sense of suffering that could be lost through resistance.

Both the examples of resistance to control (Ezzamel \& Willmott, 1998) and commitment to control (Barker, 1993) correspond to critical scholars' recognition that there is often $\alpha$ "price that has to be paid for many forms of liberation" (Alvesson \& Willmott, 1992: 447-448; see also Knights \& Morgan, 1991). This is because "emancipation is not a gift bestowed upon employees; rather it necessitates the (often painful) resistance to, and overcoming of, socially unnecessary restrictions" (Alvesson \& Willmott, 1992: 433). The analytical framework of ideal types of interaction elaborates on and explains this idea, since workers will be less inclined to resist modes of 
control when they find them to be compatible with valued aspects of their personhood. In contrast, when experienced as incompatible and as a source of suffering, workers are more likely to pursue what they consider to be moderate- to high-intensity resistance to escape the source of their suffering.

This is not to suggest that freedom from suffering is completely possible in any organizational context, or that suffering should be viewed in purely negative terms. It is suffering that encourages reflection and drives change (Fromm, 2013), as I indicated in terms of the resistance stemming from clashing combinations of control. Dejours articulated how

suffering is also a point of departure, for the concentration of subjectivity that it entails prefigures a subsequent period of expansion, redeployment, and re-expansion. Suffering is not simply a final consequence of the relationship... it is a search for the means of acting on the world (2007: 73).

Indeed, suffering is much more than a potential consequence of organizational control; it is also an antecedent of worker reflection and action. Understanding the mutually embedded nature of control and resistance necessitates a deeper examination of the explanatory power of suffering, particularly in terms of how it can sustain or encourage shifts between ideal types of control interactions. The fulfillment and suffering bound up in processes of organizational control offer insights into the modern workplace and, potentially, a focal point for future research to examine the emergence of reflection that drives resistance and change (Spicer, Alvesson, \& Körreman, 2009; Voronov, 2008). A grasp of the contextual nature of "human suffering is a prerequisite of sound emancipatory theorizing" (Knights \& Willmott, 1982: 219).

There are also societal implications stemming from the view that organizational control can sometimes be a source of suffering for workers. While the control of workers is necessary to enable organizations to operate for the benefit of many stakeholders, this should not obscure the subtle costs that this may also generate for society. As with so many other products of organization, workers' suffering can seep into the extraorganizational sphere of the everyday (Hancock \& Tyler, 2004). For instance, even highly fulfilling work can gradually produce psychological (Gill, 2015) and somatic (Michel, 2011) experiences of suffering that are not limited to the formal domain of work organizations. Normative control can adversely affect workers' relationships with their families and friends because of enhanced commitment to work (Merilöinen et al., 2004). There is therefore the potential for future research to examine how the suffering stemming from organizational control is borne by the wider society. Such research would be likely to yield a deeper and richer explanation of the variation in workers' responses to organizational control, while also illuminating how the personal consequences of organizational control can diffuse throughout society. In future research scholars should therefore seek not just to reveal the suffering that is often hidden in organizations (Maitlis, 2017) but also to understand how such suffering can impact and inform our social world.

\section{CONCLUSION}

Existing critical studies of organizational control indicate that seemingly similar combinations of control, across different organizations, yield diverse consequences for workers' compliance and resistance. To account for this diversity, I theorized that workers experience interactions between these modes along the dimensions of compatibility and coherence. I used these dimensions to construct a framework of four ideal types of interaction between modes of control, and I illustrated each through an empirical example.

The theoretical framework categorized and conceptualized workers' differing responses to control, in terms of four ideal types. I examined how workers' experiences triggered dynamic processes within each ideal type that can prompt conformance or resistance to a distinct intensity. The ideal types of interaction framework posits that organizational control can be at its most powerful when workers willingly embrace combinations of control that act in unison to suppress their suffering and facilitate a sense of fulfillment. I therefore encourage further work that brings the study of both fulfillment and suffering to the fore, not just as outcomes of control but as valuable theoretical concepts that can illuminate workplace dynamics.

\section{REFERENCES}

Abbott, P., \& Wallace, C. 1990. The sociology of the caring professions. Basingstoke, UK: Falmer Press. 
Abrams, D., \& Hogg, M. A. 1988. Comments on the motivational status of self-esteem in social identity and intergroup discrimination. European Journal of Social Psychology, 18: 317-334.

Ackroyd, S., \& Thompson, P. 1999. Organizational misbehaviour. London: Sage.

Adams, R. 2018. Universities threaten to punish striking staff over cancelled lectures. The Guardian, March 2: https:// www.theguardian.com/education/2018/mar/02/uk-universitiesthreaten-punish-striking-staff-cancelled-lectures.

Adler, P. S. 2011. Marxist philosophy and organization studies: Marxist contributions to the understanding of some important organizational forms. Research in the Sociology of Organizations, 32: 123-153.

Adler, P. S., \& Borys, B. 1996. Two types of bureaucracy: Enabling and coercive. Administrative Science Quarterly, 41: 61-89.

Adler, P. S., \& Chen, C. X. 2011. Combining creativity and control: Understanding individual motivation in largescale collaborative creativity. Accounting, Organizations and Society, 36: 63-85.

Adler, P. S., Forbes, L. C., \& Willmott, H. 2007. Critical management studies. Academy of Management Annals, l: $119-179$.

Alvesson, M., \& Körreman, D. 2004. Interfaces of control: Technocratic and socio-ideological control in a global management consultancy firm. Accounting, Organizations and Society, 29: 423-444.

Alvesson, M., \& Thompson, P. 2006. Post-bureaucracy? In A. Stephen, B. Rosemary, T. Paul, \& S. T. Pamela (Eds.), The Oxford handbook of work and organization: 485-507. Oxford: Oxford University Press.

Alvesson, M., \& Willmott, H. 1992. On the idea of emancipation in management and organization studies. Academy of Management Review, 17: 432-464.

Alvesson, M., \& Willmott, H. 2002. Identity regulation as organizational control: Producing the appropriate individual. Journal of Management Studies, 39: 619644.

Anteby, M. 2008a. Identity incentives as an engaging form of control: Revisiting leniencies in an aeronautic plant. Organization Science, 19: 202-220.

Anteby, M. 2008b. Moral gray zones: Side productions, identity, and regulation in an aeronautic plant. Oxford: Princeton University Press.

Arendt, H. 1970. On violence. New York: Houghton Mifflin Horcourt.

Ashforth, B. E., \& Humphrey, R. H. 1993. Emotional labor in service roles: The influence of identity. Academy of Management Review, 18: 88-115.

Barker, J. R. 1993. Tightening the iron cage: Concertive control in self-managing teams. Administrative Science Quarterly, 38: 408-437.

Barker, J. R. 1999. The discipline of teamwork: Participation and concertive control. London: Sage.
Barley, S. R., \& Kunda, G. 1992. Design and devotion: Surges of rational and normative ideologies of control in managerial discourse. Administrative Science Quarterly, 37: 363-399.

Bartlett, C. A., \& Ghoshal, S. 1994. Changing the role of top management: Beyond strategy to purpose. Harvard Business Review, 72(6): 79-88.

Bauman, Z. 1989. Modernity and the Holocaust. Cambridge: Polity.

Baumeister, R. F. 1987. How the self became a problem: A psychological review of historical research. Journal of Personality and Social Psychology, 52: 163-176.

Biggart, N. W., \& Delbridge, R. 2004. Systems of exchange. Academy of Management Review, 29: 28-49.

Blau, P. M. 1956. Bureaucracy in modern society. New York: Random House.

Blau, P. M., \& Schoenherr, R. A. 1971. The structure of organizations. New York: Basic Books.

Blau, P. M., \& Scott, W. R. 1962. Formal organizations: A comparative approach. Stanford, CA: Stanford University Press.

Boje, D. M. 1995. Stories of the storytelling organization: A postmodern analysis of Disney As "Tamara-Land." Academy of Management Journal, 38: 997-1035.

Bolton, S. C. 2004. A simple matter of control? NHS hospital nurses and new management. Journal of Management Studies, 41: 317-333.

Braverman, H. 1974. Labor and monopoly capital. New York: Monthly Review Press.

Brown, A. D. 2006. A narrative approach to collective identities. Journal of Management Studies, 43: 731-753.

Burawoy, M. 1979. Manufacturing consent: Changes in the labor process under monopoly capitalism. London: University of Chicago Press.

Callaghan, G., \& Thompson, P. 2001. Edwards revisited: Technical control and call centres. Economic and Industrial Democracy, 22: 13-37.

Cardinal, L. B., Sitkin, S. B., \& Long, C. P. 2004. Balancing and rebalancing in the creation and evolution of organizational control. Organization Science, 15: 411431.

Casey, C. 1995. Work, self and society: After industrialism. London: Routledge.

Casey, C. 1999. "Come, join our family": Discipline and integration in corporate organizational culture. Human Relations, 52: 155-178.

Cassell, E. J. 1982. The nature of suffering and the goals of medicine. New England Journal of Medicine, 306: 639645.

Cassell, E. J. 1991a. The nature of suffering. Oxford: Oxford University Press.

Cassell, E. J. 1991b. Recognizing suffering. Hastings Center Report, 21(3): 24-31. 
Child, J. 1972. Organization structure and strategies of control: A replication of the Aston Study. Administrative Science Quarterly, 17: 163-177.

Child, J. 1984. Organization (2nd ed.). London: Harper \& Row.

Clegg, S. 1981. Organization and control. Administrative Science Quarterly, 26: 545-562.

Clegg, S. R., Courpasson, D., \& Phillips, N. 2006. Power and organizations. London: Sage.

Collinson, D. L. 1992. Managing the shopfloor: Subjectivity, masculinity and workplace culture. Berlin: Walter de Gruyter.

Collinson, D. L. 1994. Strategies of resistance: Power, knowledge and resistance in the workplace. In J. M. Jermier, D. Knights, \& W. R. Nord (Eds.), Resistance and power in organizations: 25-68. London: Routledge.

Colville, I., Dalton, K., \& Tomkins, C. 1993. Developing and understanding cultural change in HM customs and excise: There is more to dancing than knowing the next steps. Public Administration, 71: 549-565.

Contu, A. 2008. Decaf resistance: On misbehavior, cynicism, and desire in liberal workplaces. Management Communication Quarterly, 21: 364-379.

Coombs, R., Knights, D., \& Willmott, H. C. 1992. Culture, control and competition: Towards a conceptual framework for the study of information technology in organizations. Organization Studies, 13: 51-72.

Cressey, P., \& MacInnes, J. 1980. Voting for Ford: Industrial democracy and the control of labour. Capital \& Class, 4(2): 5-33.

Cunliffe, A. L., \& Jun, J. S. 2005. The need for reflexivity in public administration. Administration \& Society, 37: 225-242.

Czarniawska-Joerges, B. 1988. Ideological control in nonideological organizations. New York: Praeger.

Dahler-Larsen, P. 1994. Corporate culture and morality: Durkheim-inspired reflections on the limits of corporate culture. Journal of Management Studies, 31: 1-18.

Deetz, S. 1995. Transforming communication, transforming business: Building responsive and responsible workplaces. Cresskill, NJ: Hampton Press.

Dejours, C. 2007. Subjectivity, work, and action. Leiden: Brill.

Delbridge, R. 1998. Life on the line in contemporary manufacturing: The workplace experience of lean production and the "Japanese" model. Oxford: Oxford University Press.

Delbridge, R., \& Ezzomel, M. 2005. The strength of difference: Contemporary conceptions of control. Organization, 12: 603-618.

Delbridge, R., \& Sallaz, J. J. 2015. Work: Four worlds and ways of seeing. Organization Studies, 36: 1449-1462.

Delbridge, R., Turnbull, P., \& Wilkinson, B. 1992. Pushing back the frontiers: Management control and work intensification under JIT/TQM factory regimes. New Technology, Work and Employment, 7: 97-106.

Drew, F. L. 1986. Suffering and autonomy. In R. DeBellis, E. Marcus, A. Kutschner, C. Smith Torres, V. Barrett, \& M.
Siegel (Eds.), Suffering: Psychological and social aspects of loss, grief, and care: 19-24. New York: Haworth Press.

Driver, M. 2002. The learning organization: Foucauldian gloom or utopian sunshine? Human Relations, 55: 33-53.

Du Gay, P. 1996. Consumption and identity at work. London: Sage.

Du Gay, P. 2000. In praise of bureaucracy: Weber - organization - ethics. London: Sage.

Durkheim, E. 2008. (First published in 1915.) The elementary forms of the religious life. (Translated by J. W. Swain.) New York: Dover Publications.

Edwards, P., Collinson, D., \& Della Rocca, G. 1995. Workplace resistance in Western Europe: A preliminary overview and a research agenda. European Journal of Industrial Relations, 1: 283-316.

Edwards, P. K. 2010. Developing labour process analysis: Themes from industrial sociology and future directions. In P. Thompson \& C. Smith (Eds.), Working life: Renewing labour process analysis: 29-46. Houndmills, UK: Palgrave.

Edwards, R. 1979. Contested terrain: The transformation of the workplace in the twentieth century. New York: Basic Books.

Edwards, R. C. 1981. The social relations of production at the point of production. In M. Zey-Ferrell \& M. Aiken (Eds.), Complex organizations: Critical perspectives: 156-182. Glenview, IL: Scott, Foresman.

Eisenhardt, K. M. 1985. Control: Organizational and economic approaches. Management Science, 31: 134-149.

Eisenhardt, K. M. 1989. Building theories from case study research. Academy of Management Review, 14: 532-550.

Eisenhardt, K. M., \& Bourgeois, L. J. 1988. Politics of strategic decision making in high-velocity environments: Toward $\alpha$ midrange theory. Academy of Management Journal, 31: 737-770.

Etzioni, A. 1975. Comparative analysis of complex organizations. London: Free Press.

Ezzamel, M., \& Willmott, H. 1998. Accounting for teamwork: A critical study of group-based systems of organizational control. Administrative Science Quarterly, 43: 358-396.

Ezzamel, M., Willmott, H., \& Worthington, F. 2001. Power, control and resistance in "the factory that time forgot." Journal of Management Studies, 38: 1053-1079.

Ezzy, D. 2001. A simulacrum of workplace community: Individualism and engineered culture. Sociology, 35: 631-650.

Ferner, A. 2000. The underpinnings of "bureaucratic" control systems: HRM in European multinationals. Journal of Management Studies, 37: 521-540.

Fineman, S., \& Sturdy, A. 1999. The emotions of control: A qualitative exploration of environmental regulation. $\mathrm{Hu}$ man Relations, 52: 631-663.

Flamholtz, E. G. 1983. Accounting, budgeting and control systems in their organizational context: Theoretical and empirical perspectives. Accounting, Organizations and Society, 8: 153-169. 
Fleming, P. 2005. Workers' playtime? Boundaries and cynicism in a "culture of fun" program. Journal of Applied Behavioral Science, 41: 285-303.

Fleming, P. 2009. Authenticity and the cultural politics of work: New forms of informal control. Oxford: Oxford University Press.

Fleming, P., \& Spicer, A. 2003. Working at a cynical distance: Implications for power, subjectivity and resistance. Organization, 10: 157-179.

Fournier, V., \& Grey, C. 2000. At the critical moment: Conditions and prospects for critical management studies. Human Relations, 53: 7-32.

Friedman, A. L. 1977a. Responsible autonomy versus direct control over the labour process. Capital \& Class, 1: 43-57.

Friedman, A. L. 1977b. Industry and labour. London: Macmillan.

Fromm, E. 2013. To have or to be? London: Bloomsbury.

Fuller, L., \& Smith, V. 1991. Consumers' reports: Management by customers in a changing economy. Work, Employment and Society, 5: 1-16.

Gabriel, Y. 1999. Beyond happy families: A critical reevaluation of the control-resistance-identity triangle. Human Relations, 52: 179-203.

Gabriel, Y. 2008. Spectacles of resistance and resistance of spectacles. Management Communication Quarterly, 21: 310-326.

Gagnon, S., \& Collinson, D. 2017. Resistance through difference: The co-constitution of dissent and inclusion. Organization Studies, 38: 1253-1276.

George, G., Corbishley, C., Khayesi, J. N., Haas, M. R., \& Tihanyi, L. 2016. Bringing Africa in: Promising directions for management research. Academy of Management Journal, 59: 377-393.

George, J. M. 2013. Compassion and capitalism: Implications for organizational studies. Journal of Management, 40: 5-15.

Giddens, A. 1984. The constitution of society: Outline of the theory of structuration. Cambridge: Polity Press.

Giddens, A. 1991. Modernity and self-identity: Self and society in the late modern age. Stanford, CA: Stanford University Press.

Gill, M. J. 2015. Elite identity and status anxiety: An interpretative phenomenological analysis of management consultants. Organization, 22: 306-325.

Gouldner, A. W. 1954. Patterns of industrial bureaucracy. New York: Free Press.

Grey, C., \& Sturdy, A. 2007. Friendship and organizational analysis: Toward a research agenda. Journal of Management Inquiry, 16: 157-172.

Grugulis, I., Dundon, T., \& Wilkinson, A. 2000. Cultural control and the "culture manager": Employment practices in a consultancy. Work, Employment and Society, 14: 97-116.

Hancock, P., \& Tyler, M. 2004. "MOT your life": Critical management studies and the management of everyday life. Human Relations, 57: 619-645.

Harris, M. 2011. Network governance and the politics of organizational resistance in UK healthcare: The National Programme for Information Technology. In S. R. Clegg, M.
Harris, \& H. Höpfl (Eds.), Managing modernity: Beyond bureaucracy? 105-129. Oxford: Oxford University Press.

Hennart, J.-F. 1993. Explaining the swollen middle: Why most transactions are a mix of "market" and "hierarchy." Organization Science, 4: 529-547.

Hirst, A., \& Humphreys, M. 2015. Configurable bureaucracy and the making of modular man. Organization Studies, 36: 1531-1553.

Hochschild, A. R. 1983. The managed heart. Berkeley: University of California Press.

Hodgson, D. E. 2004. Project work: The legacy of bureaucratic control in the post-bureaucratic organization. Organization, 11: 81-100.

Hodson, R. 1991. Workplace behaviors. Work and Occupations, 18: 271-290.

Hummel, R. P. 2007. The bureaucratic experience: The postmodern challenge. London: M. E. Sharpe.

Hyman, R. 1987. Strategy or structure? Capital, labour and control. Work, Employment and Society, 1: 25-55.

Jaeger, A. M., \& Baliga, B. R. 1985. Control systems and strategic adaptation: Lessons from the Japanese experience. Strategic Management Journal, 6: 115-134.

Jenkins, S., \& Delbridge, R. 2013. Context matters: Examining "soft" and "hard" approaches to employee engagement in two workplaces. International Journal of Human Resource Management, 24: 2670-2691.

Jennings, K., \& Western, G. 1997. A right to strike? Nursing Ethics, 4: 277-282.

Jermier, J., Knights, D., \& Nord, W. 1994. Resistance and power in organizations. London: Routledge.

Jermier, J. M. 1998. Introduction: Critical perspective on organizational control. Administrative Science Quarterly, 43: 235-256.

Johns, G. 2006. The essential impact of context on organizational behavior. Academy of Management Review, 31: 386-408.

Kalleberg, A. L., \& Griffin, L. J. 1980. Class, occupation, and inequality in job rewards. American Journal of Sociology, 85: 731-768.

Kanov, J. M., Maitlis, S., Worline, M. C., Dutton, J. E., Frost, P. J., \& Lilius, J. M. 2004. Compassion in organizational life. American Behavioral Scientist, 47: 808-827.

Kanter, R. M. 1972. Commitment and community: Communes and utopias in sociological perspective. Cambridge, MA: Harvard University Press.

Kärreman, D., \& Alvesson, M. 2004. Cages in tandem: Management control, social identity, and identification in a knowledge-intensive firm. Organization, 11: 149-175.

Knights, D., \& McCabe, D. 2000. Bewitched, bothered and bewildered: The meaning and experience of teamworking for employees in an automobile company. Human Relations, 53: 1481-1517.

Knights, D., \& Morgan, G. 1991. Corporate strategy, organizations, and subjectivity: A critique. Organization Studies, 12: $251-273$. 
Knights, D., \& Willmott, H. 1982. The problem of freedom: Fromm's contribution to a critical theory of work organisation. Praxis International, 2: 204-225.

Knights, D., \& Willmott, H. 1989. Power and subjectivity at work: From degradation to subjugation in social relations. Sociology, 23: 535-558.

Kondo, D. K. 2009. Crafting selves: Power, gender, and discourses of identity in a Japanese workplace. Chicago: University of Chicago Press.

Korzybski, A. 1958. Science and sanity: An introduction to nonAristotelean systems and general semantics (5th ed.). New York: International Non-Aristotelian Library Publishing Company.

Kunda, G. 1992. Engineering culture: Control and commitment in a high-tech corporation. Philadelphia: Temple University Press.

Landecker, W. S. 1951. Types of integration and their measurement. American Journal of Sociology, 56: 332-340.

Lawrence, T. B., \& Robinson, S. L. 2007. Ain't misbehavin: Workplace deviance as organizational resistance. Journal of Management, 33: 378-394.

Lukes, S. 1974. Power: A radical view. London: Macmillan.

Maguire, S., Phillips, N., \& Hardy, C. 2001. When "silence = death," keep talking: Trust, control and the discursive construction of identity in the Canadian HIV/AIDS treatment domain. Organization Studies, 22: 285-310.

Maitlis, S. 2009. Who am I now? Sensemaking and identity in posttraumatic growth. In L. M. Roberts \& J. E. Dutton (Eds.), Exploring positive identities and organizations: Building a theoretical and research foundation: 47-76. New York: Psychology Press.

Maitlis, S. 2017. The value of qualitative research for positive organizing. Journal of Positive Psychology, 12: 319-320.

Mars, G. 1982. Cheats at work: An anthropology of workplace crime. London: Allen \& Unwin.

Marshall, G. 1998. A dictionary of sociology. Oxford: Oxford University Press.

Martin, J., Knopoff, K., \& Beckman, C. 1998. An alternative to bureaucratic impersonality and emotional labor: Bounded emotionality at The Body Shop. Administrative Science Quarterly, 43: 429-469.

Marx, K., \& Engels, F. 2009. The economic and philosophic manuscripts of 1844 and The Communist Manifesto. (Translated by M. Milligan.) New York: Prometheus Books.

McCabe, D. 2015. The tyranny of distance: Kafka and the problem of distance in bureaucratic organizations. Organization, 22: 58-77.

McKinney, J. C. 1969. Typification, typologies, and sociological theory. Social Forces, 48: 1-12.

McLoughlin, I. P., Badham, R. J., \& Palmer, G. 2005. Cultures of ambiguity. Work, Employment and Society, 19: 67-89.

Meriläinen, S., Tienari, J., Thomas, R., \& Davies, A. 2004. Management consultant talk: A cross-cultural comparison of normalizing discourse and resistance. Organization, 11: 539-564.

Michel, A. 2011. Transcending socialization: A nine-year ethnography of the body's role in organizational control and knowledge workers' transformation. Administrative Science Quarterly, 56: 325-368.

Mintzberg, H. 1989. The structuring of organizations. In D. Asch \& C. Bowman (Eds.), Readings in strategic management: 322-352. London: Macmillan Education UK.

Mintzberg, H. 1993. Structure in fives: Designing effective organizations. Englewood Cliffs, NJ: Prentice-Hall.

Mitchell, T. R., \& Mickel, A. E. 1999. The meaning of money: An individual-difference perspective. Academy of Management Review, 24: 568-578.

Morris, T., Lydka, H., \& O'Creevy, M. F. 1993. Can commitment be managed? A longitudinal analysis of employee commitment and human resource policies. Human Resource Management Journal, 3: 21-42.

Mumby, D. K. 2005. Theorizing resistance in organization studies: A dialectical approach. Management Communication Quarterly, 19: 19-44.

Mumby, D. K., Thomas, R., Martí, I., \& Seidl, D. 2017. Resistance redux. Organization Studies, 38: 1157-1183.

Nemiroff, P. M., \& Ford, D. L. 1976. Task effectiveness and human fulfillment in organizations: A review and development of a conceptual contingency model. Academy of Management Review, 1: 69-82.

Nishiyama, K., \& Johnson, J. V. 1997. Karoshi-Death from overwork: Occupational health consequences of Japanese production management. International Journal of Health Services, 27: 625-641.

O'Doherty, D., \& Willmott, H. 2001. Debating labour process theory: The issue of subjectivity and the relevance of poststructuralism. Sociology, 35: 457-476.

Okhuysen, G., \& Bonardi, J.-P. 2011. The challenges of building theory by combining lenses. Academy of Management Review, 36: 6-11.

Orlikowski, W. J. 1991. Integrated information environment or matrix of control? The contradictory implications of information technology. Accounting, Management and Information Technologies, 1: 9-42.

Otley, D. T., \& Berry, A. J. 1980. Control, organization and accounting. In C. Emmanuel, D. T. Otley, \& K. Merchant (Eds.), Readings in accounting for management control: 231-244. Boston: Springer.

Ouchi, W. G. 1979. A conceptual framework for the design of organizational control mechanisms. Management Science, 25: 833-848.

Ouchi, W. G., \& Johnson, J. B. 1978. Types of organizational control and their relationship to emotional well being. Administrative Science Quarterly, 23: 293-317.

Özkazanç-Pan, B. 2008. International management research meets "the rest of the world." Academy of Management Review, 33: 964-974. 
Pfeffer, J. 2018. Dying for a paycheck. New York: Harper Business.

Prasad, A., \& Prasad, P. 1998. Everyday struggles at the workplace: The nature and implications of routine resistance in contemporary organizations. Research in the Sociology of Organizations, 15: 225-257.

Rafaeli, A., \& Pratt, M. G. 1993. Tailored meanings: On the meaning and impact of organizational dress. Academy of Management Review, 18: 32-55.

Reed, M. 2010. Control in contemporary work organizations. In P. Blyton, E. Heery, \& P. Turnbull (Eds.), Reassessing the employment relationship: 41-70. Basingstoke, UK: Palgrave MacMilllan.

Reed, M. 2011. The post-bureaucratic organization and the control revolution. In S. R. Clegg, M. Harris, \& H. Höpfl (Eds.), Managing modernity: Beyond bureaucracy? 230-256. Oxford: Oxford University Press.

Ritzer, G. 2008. The McDonaldization of society. London: Pine Forge Press.

Robertson, M., \& Swan, J. 2003. "Control-what control?" Culture and ambiguity within a knowledge intensive firm. Journal of Management Studies, 40: 831-858.

Rodrigues, S. B., \& Collinson, D. L. 1995. "Having fun"? Humour as resistance in Brazil. Organization Studies, 16: 739-768.

Rose, N. 1990. Governing the soul: The shaping of the private self. Florence, KY: Taylor \& Frances/Routledge.

Rosenthal, P. 2004. Management control as an employee resource: The case of front-line service workers. Journal of Management Studies, 41: 601-622.

Rosenthal, P., Hill, S., \& Peccei, R. 1997. Checking out service: Evaluating excellence, HRM and TQM in retailing. Work, Employment and Society, 11: 481-503.

Ryan, R. M., \& Deci, E. L. 2001. On happiness and human potentials: A review of research on hedonic and eudaimonic well-being. Annual Review of Psychology, 52: 141-166.

Scott, J. C. 1990. Domination and the arts of resistance: Hidden transcripts. Yale, CT: Yale University Press.

Snell, S. A. 1992. Control theory in strategic human resource management: The mediating effect of administrative information. Academy of Management Journal, 35: 292-327.

Spicer, A., Alvesson, M., \& Kärreman, D. 2009. Critical performativity: The unfinished business of critical management studies. Human Relations, 62: 537-560.

Storey, J. 1980. The challenge to management control. London: Kogan Page.

Storey, J. 1985. The means of management control. Sociology, 19: 193-211.

Sturdy, A., Fleming, P., \& Delbridge, R. 2010. Normative control and beyond in contemporary capitalism. In P. Thompson \& C. Smith (Eds.), Working life: Renewing labour process analysis: 113-135. Houndmills, UK: Palgrave.

Thomas, R. 2009. Critical management studies on identity: Mapping the terrain. In M. Alvesson, T. Bridgman, \& H. Willmott (Eds.), The Oxford handbook of critical management studies: 167-185. Oxford: Oxford University Press.
Thomas, R., \& Davies, A. 2005. Theorizing the micro-politics of resistance: New public management and managerial identities in the UK public services. Organization Studies, 26: 683-706.

Thomas, R., Hardy, C., Cutcher, L., \& Ainsworth, S. 2014. What's age got to do with it? On the critical analysis of age and organizations. Organization Studies, 35: 1569-1584.

Thomas, R., Sargent, L. D., \& Hardy, C. 2011. Managing organizational change: Negotiating meaning and power-resistance relations. Organization Science, 22: 22-41.

Thompson, P. 2003. Disconnected capitalism: Or why employers can't keep their side of the bargain. Work, Employment and Society, 17: 359-378.

Thompson, P., \& McHugh, D. 1995. Work organisations: A critical introduction. Hampshire, UK: Palgrave Macmillan.

Thompson, P., \& van den Broek, D. 2010. Managerial control and workplace regimes: An introduction. Work, Employment and Society, 24: 1-12.

Tompkins, P. K., \& Cheney, G. 1985. Communication and unobtrusive control in contemporary organizations. In R. D. McPhee \& P. K. Tompkins (Eds.), Organizational communication: Traditional themes and new directions: 179-210. Newbury Park, CA: Sage.

Victor, B., \& Stephens, C. 1994. The dark side of the new organizational forms: An editorial essay. Organization Science, 5: 479-482.

Voronov, M. 2008. Toward engaged critical management studies. Organization, 15: 939-945.

Voronov, M., \& Vince, R. 2012. Integrating emotions into the analysis of institutional work. Academy of Management Review, 37: 58-81.

Walton, E. J. 2005. The persistence of bureaucracy: A metaanalysis of Weber's model of bureaucratic control. Organization Studies, 26: 569-600.

Wartenberg, T. E. 1982. "Species-being" and "human nature" in Marx. Human Studies, 5: 77-95.

Watson, T. J. 1997. The labour of division: The manager as "self" and "other." Sociological Review, 45(Supplement 1): $139-152$.

Weber, M. 1946. From Max Weber: Essays in sociology. London: Routledge.

Weber, M. 1978. Economy and society. London: University of California Press.

Weick, K. E. 1989. Organized improvisation: 20 years of organizing. Communication Studies, 40: 241-248.

Willmott, H. 1993. Strength is ignorance; slavery is freedom: Managing culture in modern organizations. Journal of Management Studies, 30: 515-552.

Willmott, H. 1997. Rethinking management and managerial work: Capitalism, control, and subjectivity. Human Relations, 50: 1329-1359.

Willmott, H. 2005. Theorizing contemporary control: Some post-structuralist responses to some critical realist questions. Organization, 12: 747-780. 
Willmott, H. 2011. Back to the future: What does studying bureaucracy tell us? In S. R. Clegg, M. Harris, \& H. Höpfl (Eds.), Managing modernity: Beyond bureaucracy? 257294. Oxford: Oxford University Press.

Zanoni, P., \& Janssens, M. 2007. Minority employees engaging with (diversity) management: An analysis of control, agency, and micro-emancipation. Journal of Management Studies, 44: 1371-1397.

Zaza, C., Charles, C., \& Muszynski, A. 1998. The meaning of playing-related musculoskeletal disorders to classical musicians. Social Science \& Medicine, 47: 2013-2023.

Michael Gill (Michael.Gill@sbs.ox.ac.uk) is an associate professor at the Saïd Business School, University of Oxford. He received his doctorate from the University of Oxford. His research focuses on the experience of modern work, particularly in terms of workers' emotions and identities. 
Copyright of Academy of Management Review is the property of Academy of Management and its content may not be copied or emailed to multiple sites or posted to a listserv without the copyright holder's express written permission. However, users may print, download, or email articles for individual use. 